\title{
إمكانية تطبيق معايير الجودة الثاملة في جامعة ديالى
}

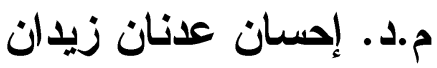 \\ جامعة ديالى/ كلية التربية للعلوم الانسانية \\ Ihsanadnan84@gmail.com
}

$$
\begin{aligned}
& \text { تاريخ الاستلام : r r 19/1 r r }
\end{aligned}
$$

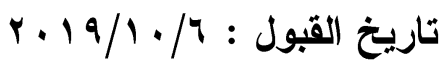

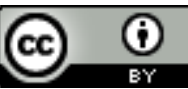

This work is licensed under a Creative Commons Attribution 4.0 International License

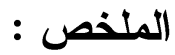

هدفت الدراسة الحالية الى التعرف على إمكانية تطبيق معايير الجودة الثاملة في جامعة ديالى من وجهة

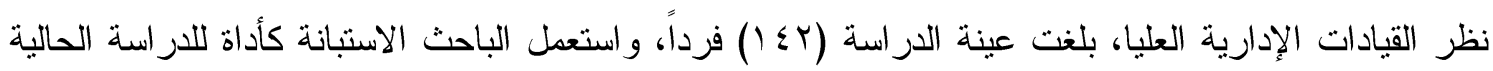

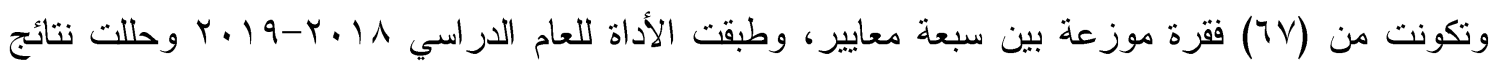
الدراسة باستعمال الوسائل الإحصائية المناسبة. أسفرت النتائج عن الآتي: ا - حازت معايير الجودة الثاملة المحددة في الدراسة الحالية على إمكانية التطبيق في جامعة ديالى مع

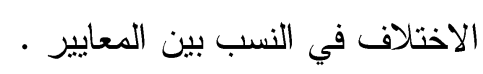

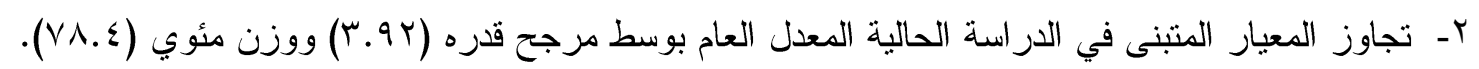

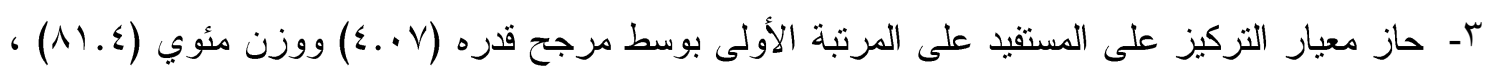

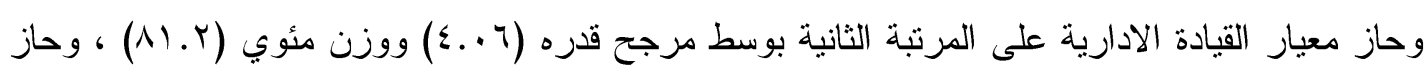

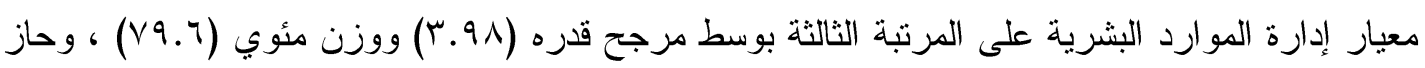

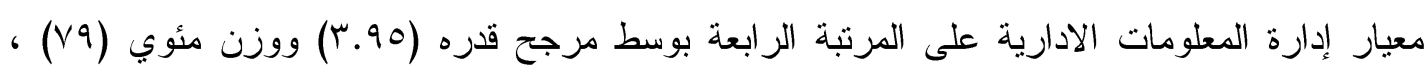

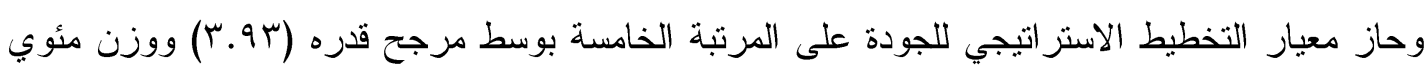

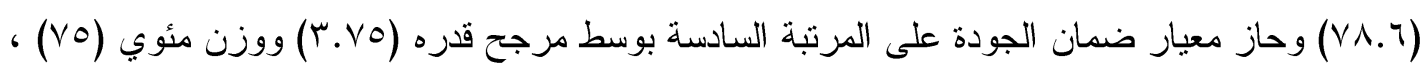

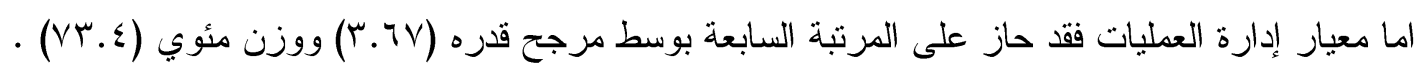
ع- حازت الفقرة تسلسل (1) التي نصها (اقتتاع إدارة الجامعة بدعم تطبيق معايير الجودة الثاملة) ضمن معيار

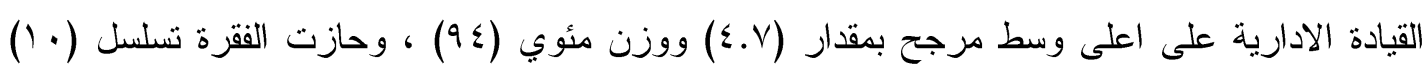

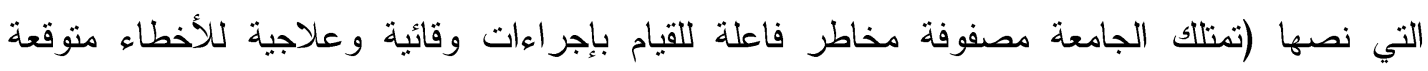

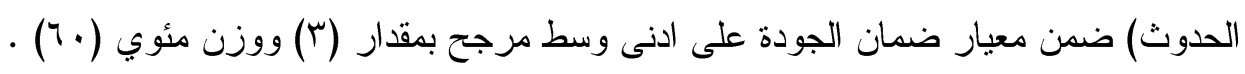




\title{
The Possibility of Applying Comprehensive Quality Standards at University of Diyala
}

\author{
Inst. Ihsan Adnan Zaidan (M.A.) \\ University of Diyala College of Education for Humanities \\ Ihsanadnan84@gmail.com
}

\begin{abstract}
The current study aims to identify the possibility of applying comprehensive quality standards at University of Diyala from the viewpoint of senior management leaderships. The sample of the study is (142) individuals. The researcher uses the questionnaire as a tool for the current study which consists of (67) items divided on seven criteria, and the tool is applied for the academic year 2018-2019. The results of the study have been analyzed by using the appropriate statistical means.

The results are as follows:

1. In the current study the comprehensive standard quality criteria gain the ability of applying to University of Diyala with different ratios between the standards.

2. In the current study the adopted standard exceeded the overall average with a weighted average of (3.92) and a percentage weight (78.4).

3. The beneficiary focus standard is ranked the first with a weighted average (4.07) and a percentage weight (81.4). The management leadership standard is the second in weighted position (4.06) and percentage weight (81.2), human resources management standard is ranked the third in a weighted center (3.98) and a percentage weight (79.6), the Informational Administrative Standard (IAS) is ranked the fourth in a weighted average (3.95) and a percentage weight (79), the standard of Strategic Quality Planning (SQP) is ranked the fifth in a weighted average (3.93), a percentage weight (78.6), quality assurance standard is ranked the sixth in a weighted average (3.75) and a percentage weight (75), and the standard of operational management is ranked the seventh in a weighted average (3.67) and a percentage weight (73.4).

4. Item No. 1, which reads as (the conviction of university administration's to support the implementation of comprehensive quality standards) within the administrative leadership standard, receives the highest weight average (4.7) and a percentage weight (94), and item No. (10) which reads (the university has an effective risk matrix for preventive and therapeutic measures for errors that are expected to occur) within the quality assurance standard at the lowest weighted medium of (3) and a percentage weight (60).
\end{abstract}

Key Word: comprehensive quality, senior management leaderships, University of Diyala 


\section{الفصل الاول}

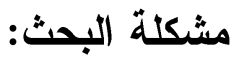

تضع كثثر من الدول المنقدمة نصب عينها اليوم اعداد جامعاتها وتتميتها وتطويرها ؛ لدور المؤثر في تحسين التعلم وتحقيق أهدافه المبتغاة ، ليؤثر ايجاباً في تنمية المجتمع وتطوير ابنائه لمواكبة التقدم العلمي و المعرفي و التكنولوجي الذي يشهده عصرنا الحالي ، ويتضح اهتمام الدول المتقدمة بالتعليم الجامعي ؛ لأنه

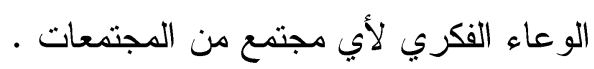

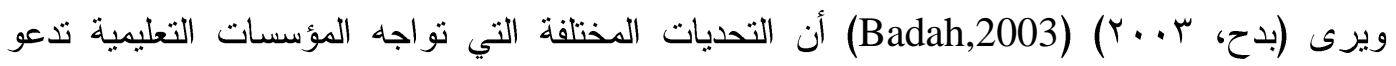
القائمين على شؤون التعليم بالعمل على مواجهة التحديات من خلال تحسين جودة التعليم الذي يُعد هدفاً أساساً

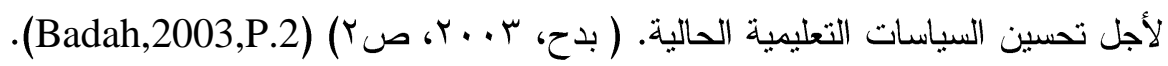

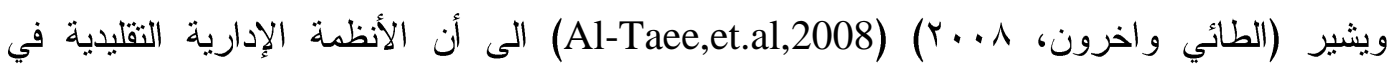

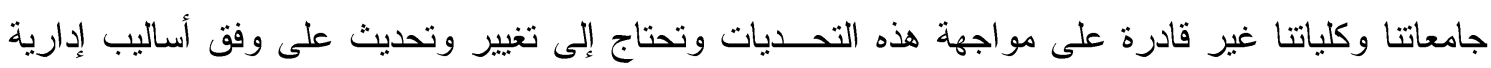

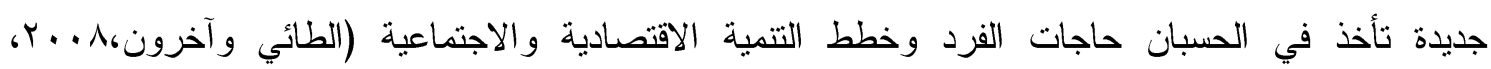
ص صهr (1) (Al-Taee,et.al,2008,P.135.). وتو اجه المؤسسات الجامعية العراقية تحديات غير مسبوقة، نتيجة للتغيرات و التطورات المتمثلة في ثورة

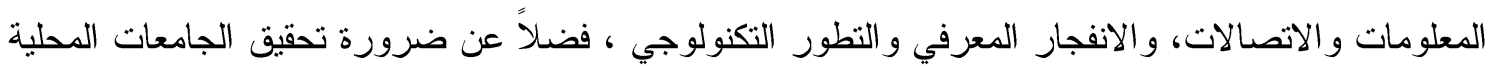

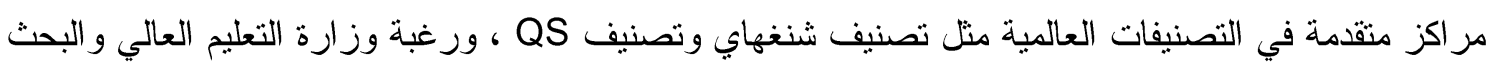
العلمي في تحقيق المؤسسة الجامعية الاعتماد الاكاديمي وتتطلب هذه التحديات تطوير الموارد البشرية و إيجاد

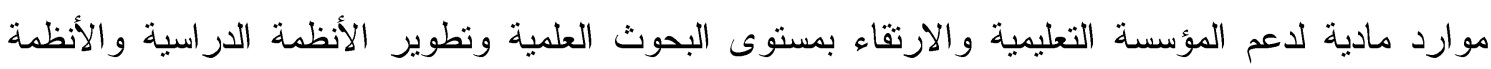

و إدارة الجودة الثاملة هي أحدى النظم المتبعة لمواجهة تلك التحديات والأزمات ؛ لأنها نظام قائم على التى

تحسين الأداء المستمر في مستويات العمـلية التعليمية والإدارية جميعها ، وفي كل المجالات الوظيفية لإدية للمؤسسة

التعليمية وذلك باستعمال كافة الموارد البشرية و المالية المتاحة. (Brocka,1992,P.12)

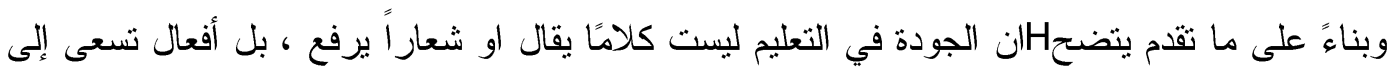

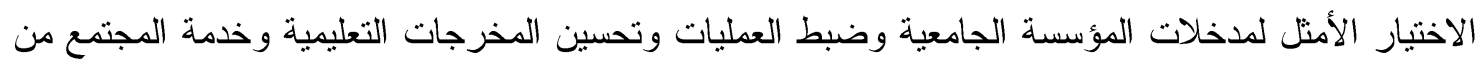
خلال الجهود المبذولة من المنتسبين جميعهم بمختلف تخصصاتهم الوظيفية ، مما يتطلب تطبيق مجموعة من

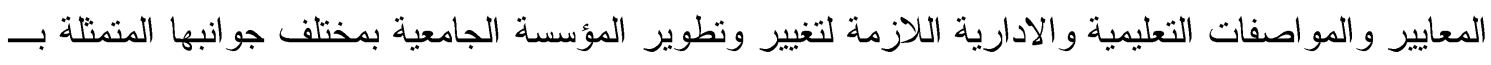

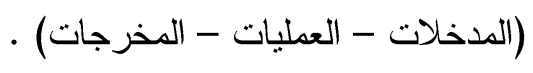

وبذلك تبرز مشكلة البحث الحالي من خلال السؤال الآتي:

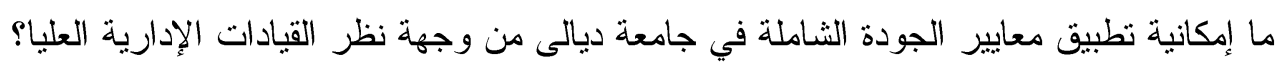
أهمية البحث: مانه:

تسعى الدول لتوفير الملاكات البشرية المؤهلة لكي تكون لها عونا لتحقيق ما تتشده من التتمية الثاملة التي تزيد من رفاه وازدهار المجتمع ، ولعل الآلية الوحيدة لتوفير مثل هذه الملاكات هي وجود نظام تعليمي لنوني 
عالٍ متميز يأخذ بالحسبان الجودة في بر امجه من جهة ومو اعمة مخرجاته لميدان العمل من جهة أخرى (توما،

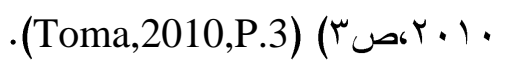

وتحتل المؤسسة الجامعية وجودتها أهمية كبيرة ؛ لأنها تؤثر في المجتمع كله مؤسسات و أفراد ، ويتوقف

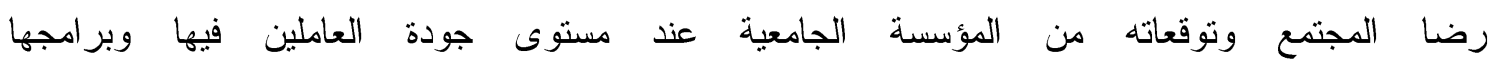

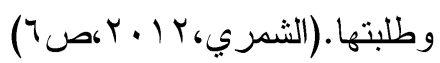

(Al-Shamary,2012,P.6)

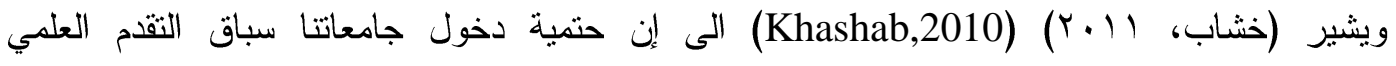
و المعرفي والاداري الذي يشهده عصرنا الحالي ضرورة تتطلبها المتغيرات المحلية و العالمية، وأن المشاركة الفعالة في الوسائل و الأساليب التعليمية المختلفة ، و القضاء على الهدر في الأنشطة و الثروات تمنح عطاءً كبيراً

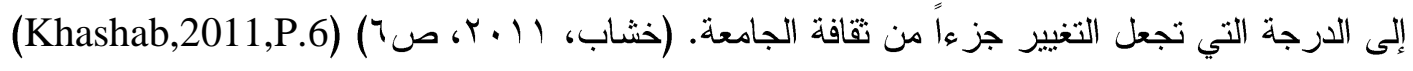
وبما أن الجودة الثاملة قد أصبحت ضرورة ملحة في أداء المؤسسات الإنتاجية و الخدمية في تحسين

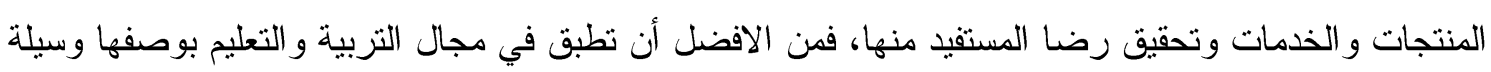

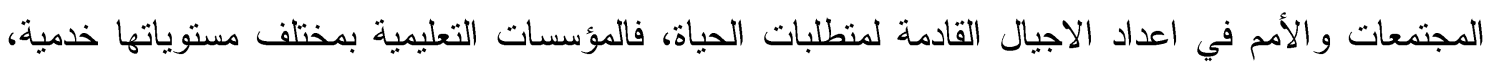
نتاجها التعليم واعداد الكوادر البشرية التي يحتاجها المجتمع في كل مجالات الحياة. و الحاجة إلى جودة هذه

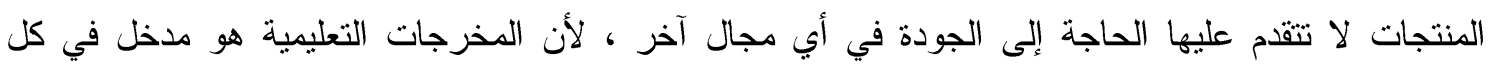

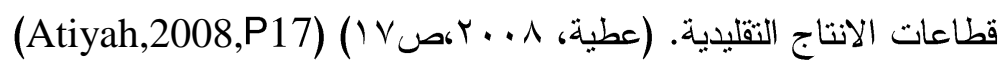
ويأتي الاهتمام المتزايد بمعايير الجودة الثاملة من الاقتناع بأن جودة التعليم العالي تكون في وجود

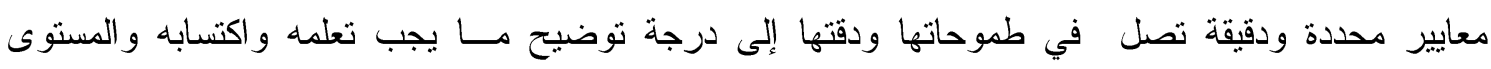

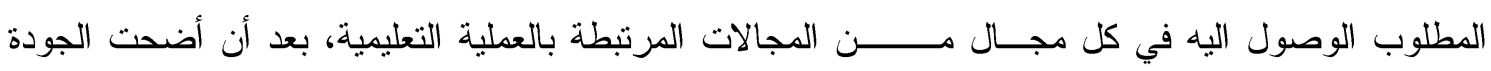

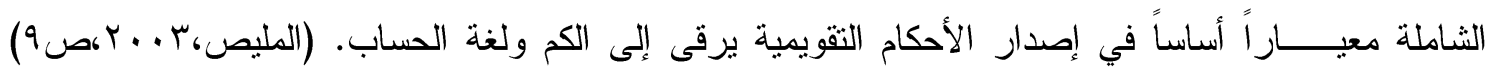

(Al-Malees,2003,P.9)

و الجودة في التعليم تعدّ من أهم الوسائل والأساليب الناجحة في تطوير وتحسين بنية النظام التعليمي

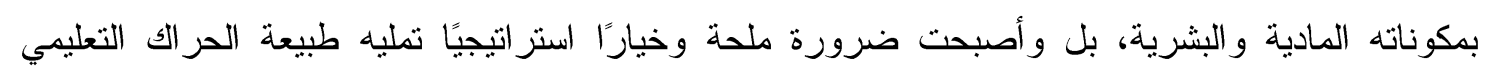

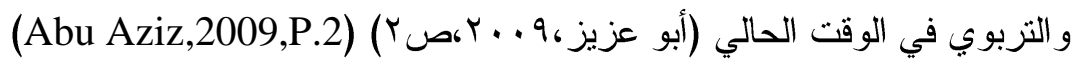

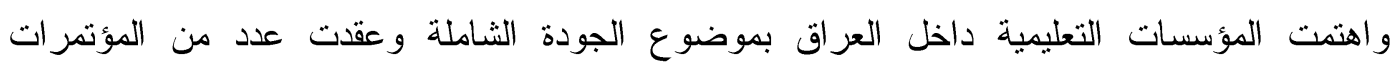
و الندوات منها : اما في العراق فقد عقدت جامعة بابل عام V. . . ندوة عن الجودة الثاملة بعنوان " نبدأ الخطوة

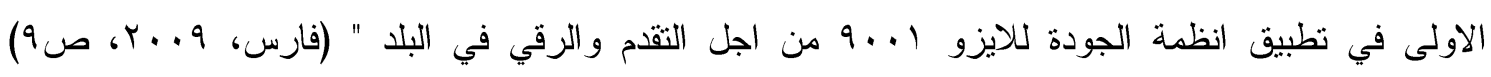

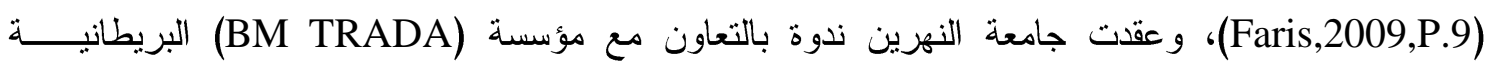

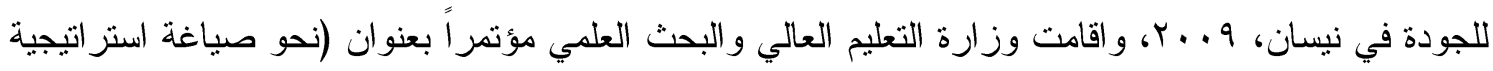

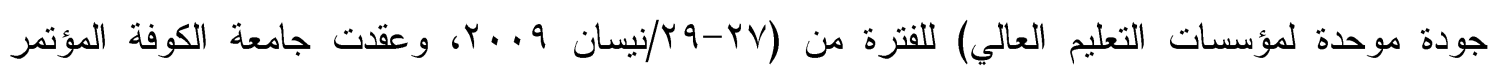

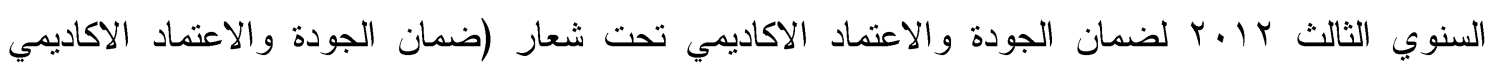
رؤيتنا لتطوير التعليم العالي ) ) و أثثارت كثير من الدراسات المحلية والعربية والاجنبية الى أهمية الجودة الثاملة في العملية التعليمية

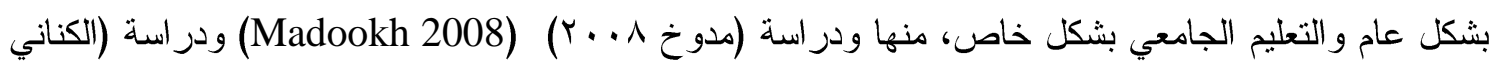




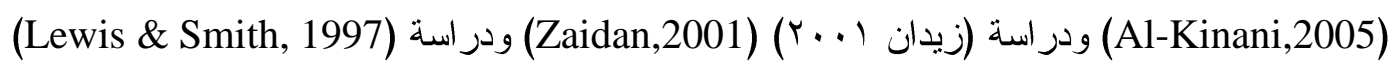
يعد تطبيق معايير الجودة الثشاملة في جامعة ديالى غاية في الأهمية، وذلك من أجل الارتقاء بها إلى ودلى معدلات عالية من الأداء وتحسين جودة الخدمات ورفع مستوى مخرجاتها التعليمية، ومواجهة التحديات المختلفة

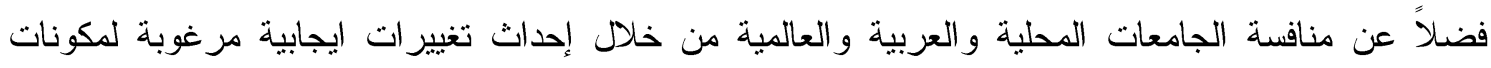
المؤسسة الجامعية المختلفة المتمثلة بــ(المدخلات - العمليات - المخرجات). وفي ضوء ما تقدم يمكن تلخيص أهمية البحث بالآتي:

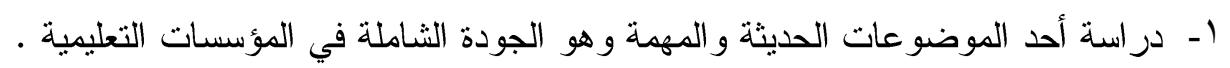

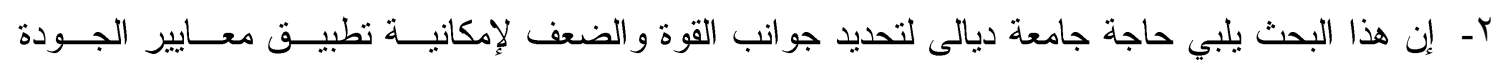
الثاملة.

r- حاجة المؤسسة الجامعية لهذه الدراسات التي يمكن ان تسهم في تغيير الأنظمة الإدارية وتطوير الأداء فيها وتحسينه. ع- اغناء المكتبة التربوية و الادارية وحاجتها إلى هذه البحوث. اهداف البحث : (1) ا - - تحديد معايير الجودة الشاملة. r- ت تعرف درجة إمكانية تطبيق معايير الجودة الثشاملة في جامعة ديالى. حدود البحث : - تحدد هذا البحث بــــ (دراسة إمكانية تطبيق معايير الجودة الثاملة من وجهة نظر رئيس الجامعة

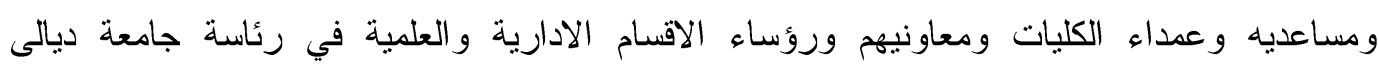

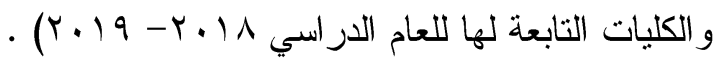
تحديا المصطلحات: اولاً: المعايير:

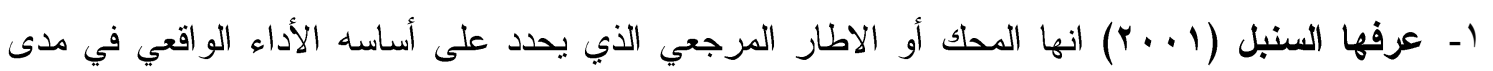

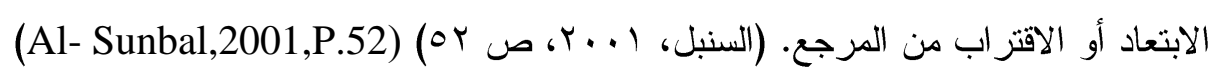

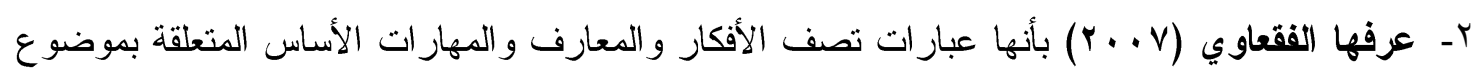

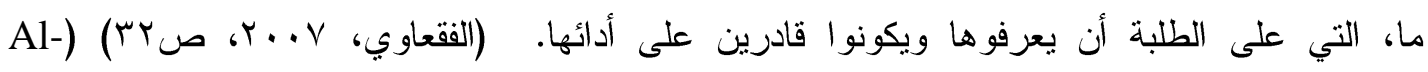
(Faqawi,2007,P.32

ثانياً : الجــودة الثـاملة:

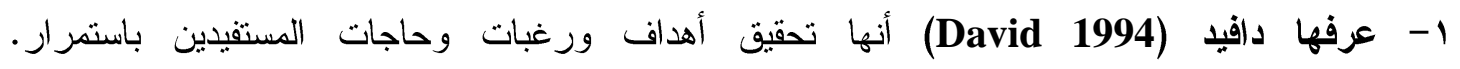
(David,1994,P:18) Y- عـرفها (عشيبة . . . †) جملة من المعايير والخصائص التي ينبغي أن تتو افر في جميع عناصر العملية

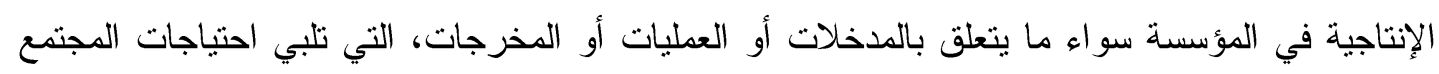


ومتطلباته، ورغبات المستقيدين، وتتحقق من خلال الاستخدام الفعال لجميع العناصر البشرية و المادية في

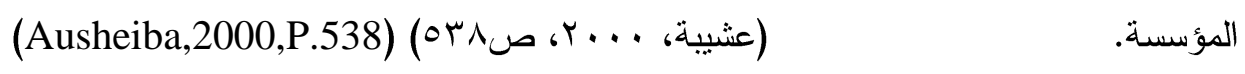
ثالثاً: جامعة ديالى: - مؤسة. هي إحدى مؤسسات التعليم العالي تعني بالتزبية و الثقافة والتعليم ، وتعمل على تأهيل الملاكات البشرية

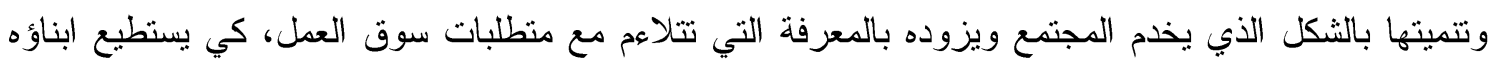

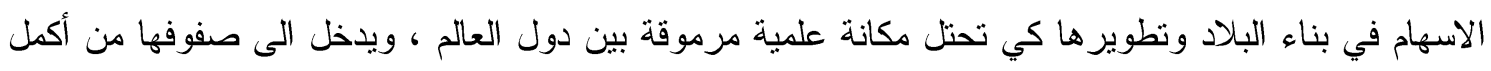

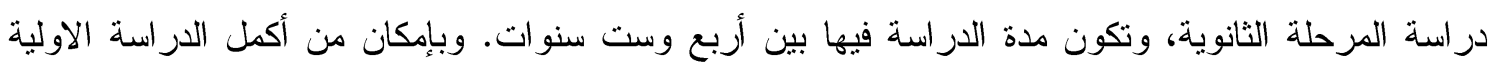

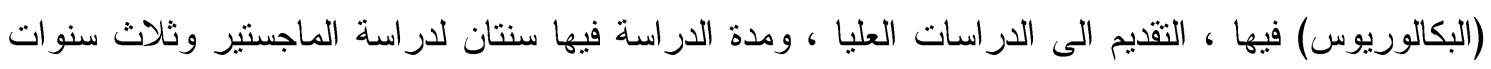
لدار اسة الدكتور اه. وتضم جامعة ديالى أربع عشرة كلية بالاختصاصات المختلفة (العلمية - الانسانية) وهي: 1 - ملية التربية الاساسية

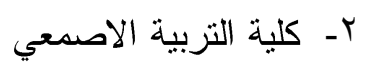
r- كلية الهندسة ع- كلية التزبية الرياضية ๑- ـ كلية العلوم T- كلية القانون و العلوم السياسية - V - كلية الطب البيطري 1- كلية الطب 9- كلية الزراعة المبه

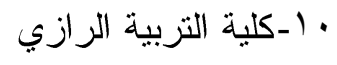
1 1 -كلية الادارة و الاقتصساد r ا ا-كلية العلوم الاسلامية عا -كلية الفنون الجميلة ـ ا -كلية التزبية المقداد.

$$
\begin{aligned}
& \text { الفصل الثاني } \\
& \text { در اسات سابقة: }
\end{aligned}
$$

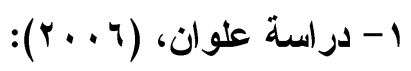

(إدارة الجودة الثاملة و إمكانية تطبيقها في كليات جامعة التحدي) (لبات

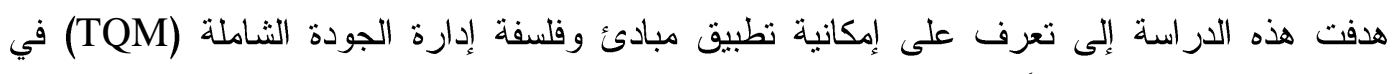

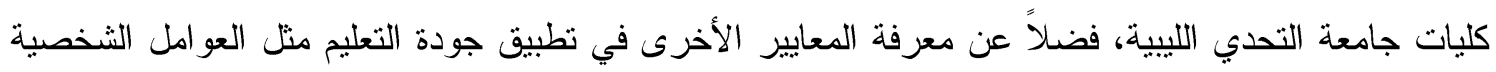

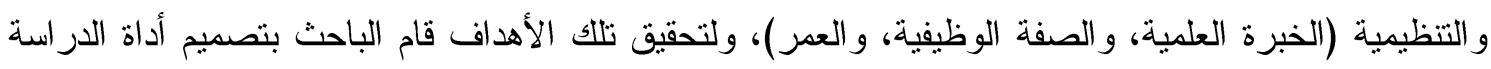
و هي استبانة تعتمد على خمسة مجالات مقترحة للجودة الثاملة في التعليم وهي (الإدارة الجامعية و النتريعات 
و اللوائح الجامعية و التركيز على العميل الجامعي وتقيم الوقاية والتحسين المستمر ) وجرى قياس كل مجال من

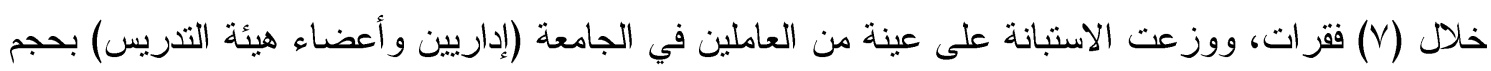

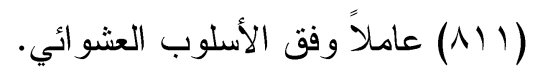
وتوصلت الدراسة إلى أن إمكانية تطبيق مبادئ وفلسفة إدارة الجودة الثاملة من وجهة نظر عينة الدراسة

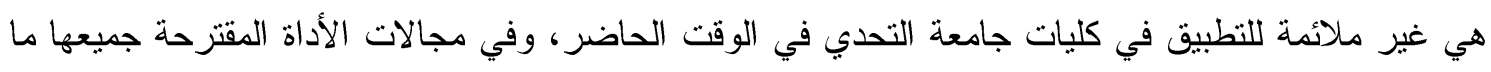

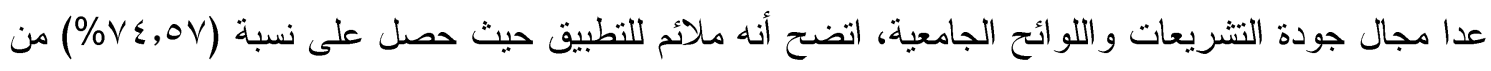

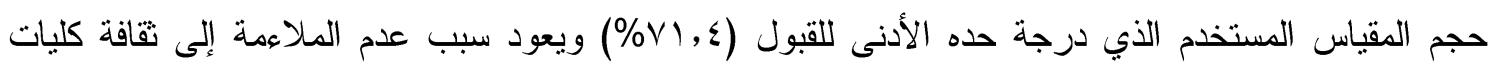

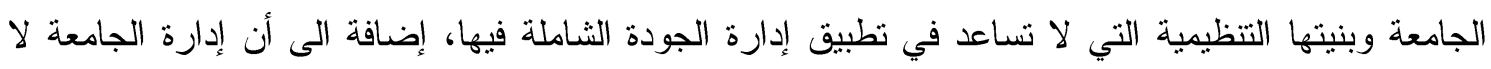

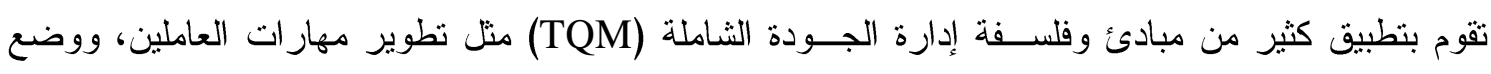

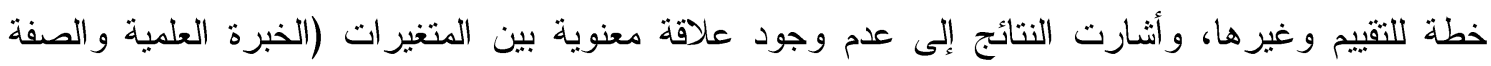
الوظيفية و العمر ) و إمكانية تطبيق مجالات إدارة الجودة الشاملة في كليات الجامعة.

(درجة إمكانية تطبيق مبادئ إدارة الجودة الثاملة في الجامعات الأردنية)

$$
\text { r }
$$

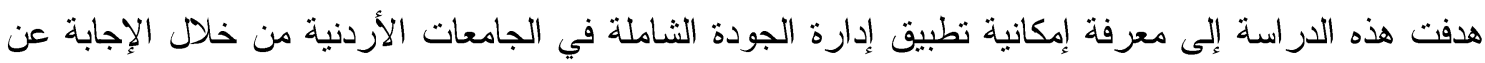
الأسئلة الآتية:

1 - ما درجة إمكانية تطبيق مبادئ إدارة الجودة الثاملة في الجامعات الأردنية؟

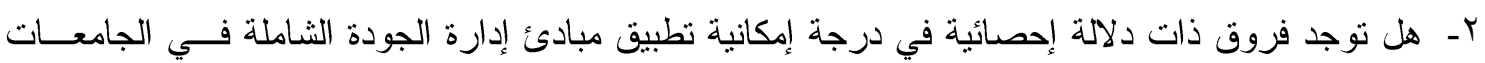

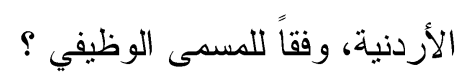

وقد تكونت المبادئ من عشرة مجالات هي (القيادة ورسالة الجامعة و الثقافة التظظيمية ونظام حوسبة

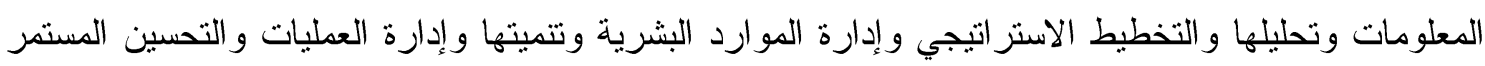

ورضا العملاء و التغذية الراجعة).

وللتحقق من درجة إمكانية تطبيق هذه المبادئ للجامعات، قام الباحث بعرضها على على عينــة الدر اســـة المكونـــة

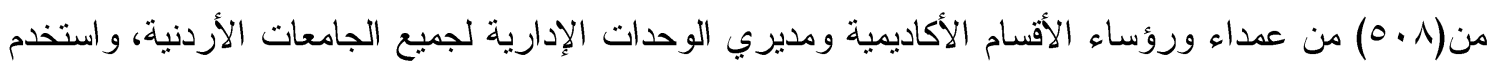

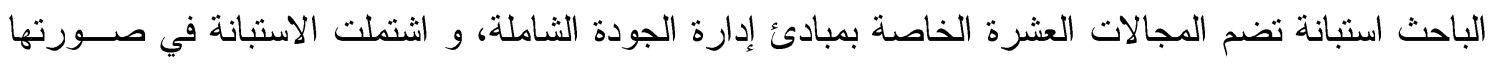

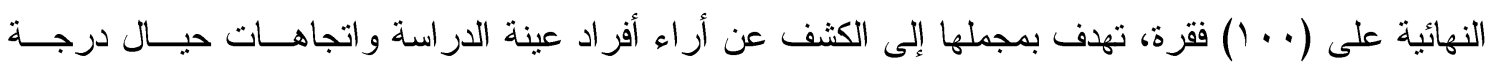

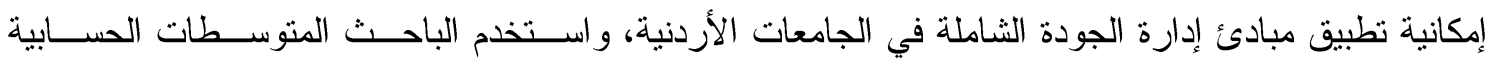

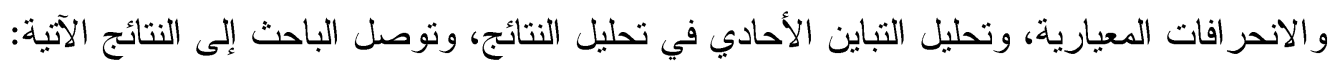
- جاءت درجة إمكانية تطبيق مبادئ إدارة الجودة الثاملة في الجامعات الأردنية كبيرة.

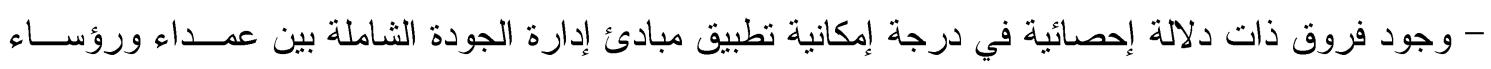
الأقسام الأكاديمية ومديري الوحدات الإدارية في الجامعات الأردنية لصالح العدداء.

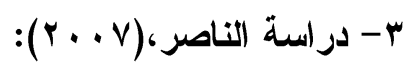




\section{(بناء أنموذج لإدارة الجودة الثاملة في جامعة بغداد)}

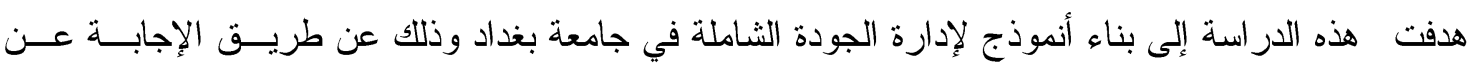
السؤ الين الآتيين: - الين

1 - ما التصور المقترح لأنموذج إدارة الجودة الثاملة في جامعة بغداد. r- ما المعوقات التي تحول دون تطبيق هذا الأنموذج في جامعة بغداد.

و الإجابة على الفرضية الآتية:

- لا توجد فروق ذوات دلالة إحصائية ما بين المستويات الإدارية لأفر اد عينة البحث في إمكانية تطبيق هــذا الأنموذج.

وتحددت الدراسة بجميع مدراء الوحدات الإدارية المختلفة في جامعة بغداد، المتمثلة بعداء الكليات و المعاهد العليا ومعاونيهم ومدراء المراكز البحثية ورؤساء الأقسام العلمية ومدراء الأقسام الإدارية للعام

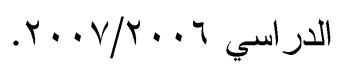
ولتحقيق أهداف البحث اعتمد الباحث أسلوب المنهج الوصفي التحليلي، وتكون مجتمع البحث من (19) فرداً يمثلون العدداء ورؤساء الأقسام العلمية ومدر اء المراكز البحثية ومدراء الوحدات الإدارية المختلفة في من الهي الكليات و المعاهد العليا التابعة إلى جامعة بغداد.

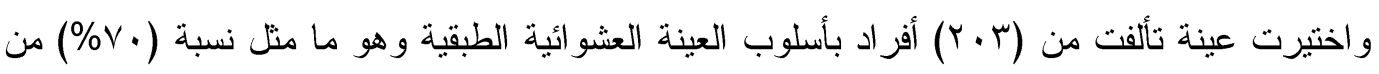
مجتمع البحث. و اعتمد الباحث الاستبانة أداة للبحث، و اشتملت الأداة على (• () محاور وتضم (919) فقرة موزعة على محاور الأنموذج وهي (القيادة ورسالة الجامعة و البيئة التنظيمية و التخطيط الاستراتيجي ونظم المعلومات و إدارة

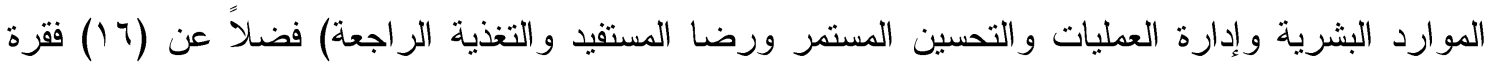
للكشف عن المعوقات التي تحول دون تطبيق هذا الأنموذج في جامعة بغداد.

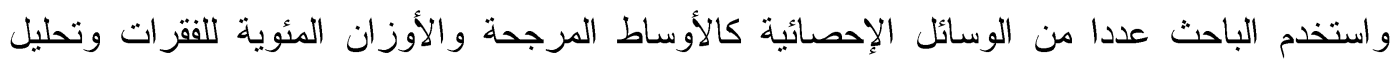
التباين الأحادي لمعرفة دلالة الفروق. وتوصل الباحث إلى نتائج عدة منها ما يأني:

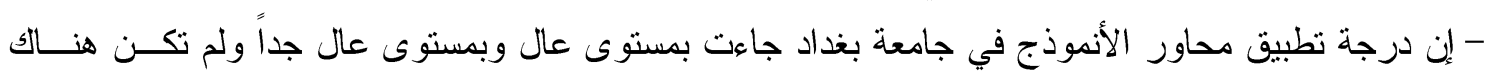
محاور دون ذلك.

- إن (عدم تو افر صورة واضحة لدى الإدارة و الموظفين في جامعة بغداد عن إدارة الجودة الثاملة) من أعلــى الفقرات المعوقة للنطبيق و أهمها. - لم تظهر فروق ذوات دلالة إحصائية بين المستويات الإدارية لإفراد عينة البحث في تطبيق محاور الأنـــوذج

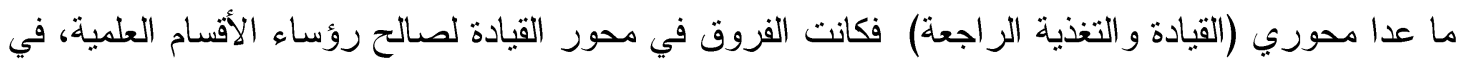
حين كانت الفروق لصالح العمداء ومعاونيهم في محور التغذية الر اجعة. 


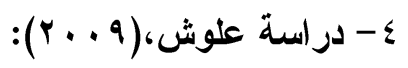

(متطلبات إدارة الجودة الثشاملة في كليتي التربية والتربية الأساسية في الجامعة المستنصرية)

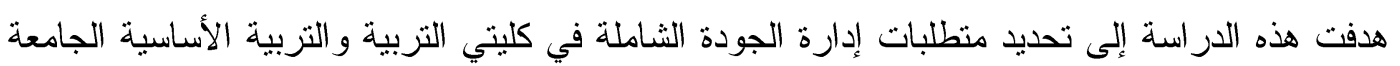
المستتصرية، وتعرف مدى ممارسة هذه المتطلبات في الكليتين، فضلاً عن معرفة الفروق في استجابات أفراد عينة البحث بحسب متغيري (الجنس و الكلية). وتحددت الدراسة بأعضاء هيئة التدريس من هم بدرجة مدرس وصعوداً في الكليتين للعام الدراسي

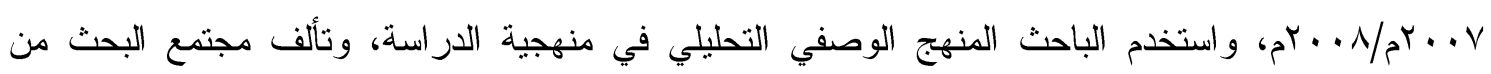

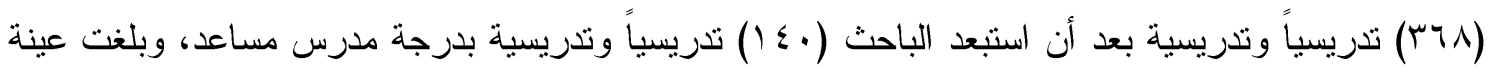

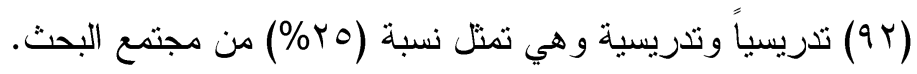

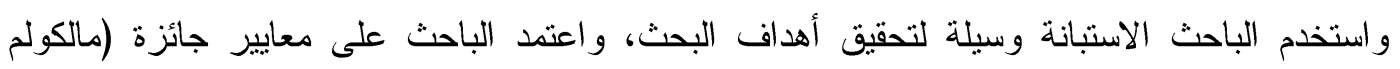

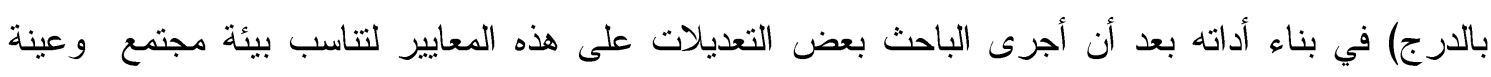

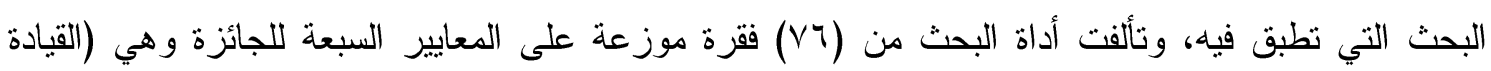
الإدارية والتخطيط الاستراتيجي للجودة ونظم المعلومات الإدارية وإدارة الموارد البشرية وتصميم العمليات

وتقويم الجودة ورضا المستقيد). واستخدم الباحث عدداً من الوسائل الإحصائية في تحليل النتائج وتفسيرها منها المتوسطات الحسابية و الانحر افات المعيارية، و الاختباري التائي. وتوصل الباحث إلى نتائج عدة منها: - - مإن ممارسة متطلبات إدارة الجودة الثاملة في الكليتين جاءت بمستوى متوسط - - لم تظهر فروق ذات دلالة إحصائية في استجابات عينة البحث بحسب متغيري (الجنس و الكلية). - موازنة الدراسات السابقة:

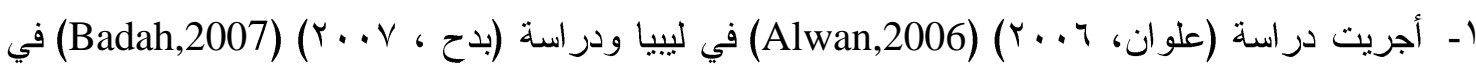

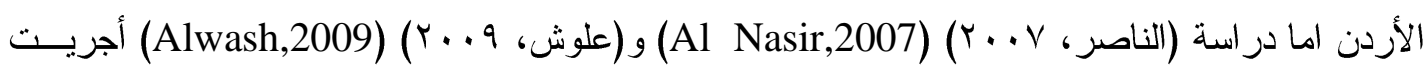
في العراق. r- تباينت أهداف الدراسات، فدر اسة (علوان، 7 . . r) (Alwan,2006) هدفت الى تعرف على إمكانية تطبيق

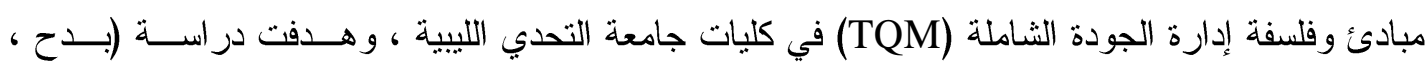
(Badah,2007) (Y . . V

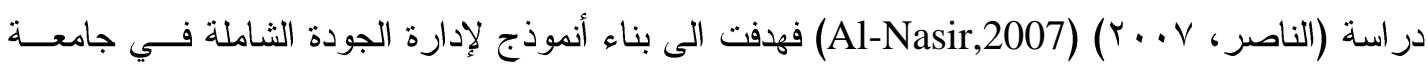

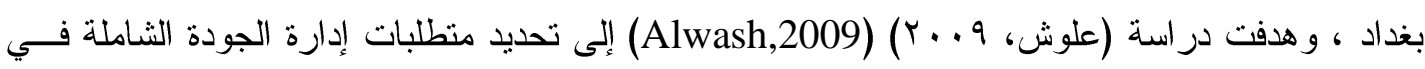
كليتي التربية و التربية الأساسية الجامعة المستتصرية، وتعرف ولثن مدى ممارسة هذه المنطلبات في الكليتين .

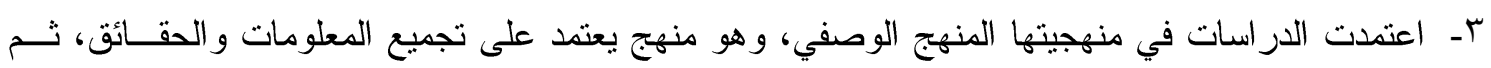

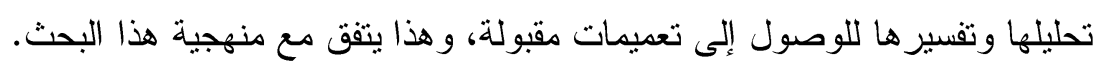


عـ - اختلفت الدراسات من حيث مجتمعاتها وعيناتها، فبعض الدراسات اقتصرت عيناتها علــى العـاملين فــي

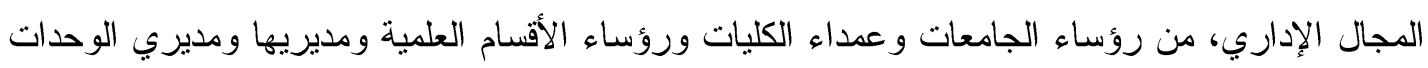

$$
\text { الإدارية. }
$$

ه- تتوعت الدراسات من حيث استخدامها الوسائل الإحصائية لمعالجة البيانات، لتعدد أهداف هـذه الدراســات

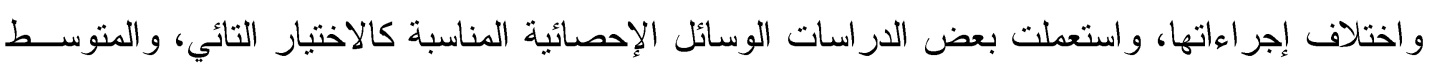

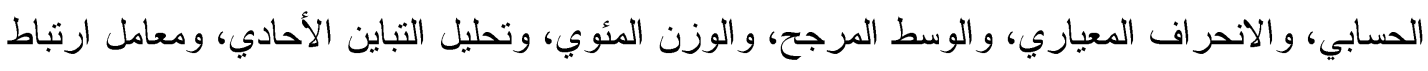
بيرسون، ومعادلة ألفا كورنباخ. جوانب الإفادة من الار وسات السابقة

1- التعرف على منهجية الدراسات السابقة والإفادة منها في منهجية الدراسة الحالية.

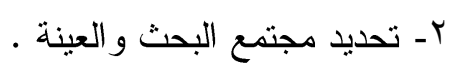
r- تحديد وبناء أداة الدراسة الحالية.

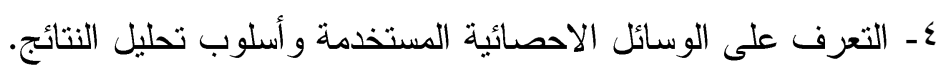

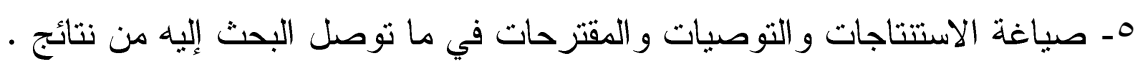

\section{الفصل الثالث}

\section{منهج البحث و إجراعاته}

يتضمن هذا الفصل منهج البحث والإجراءات المتبعة في تحديد مجتمع البحث، واختيار العينة، وكيفية

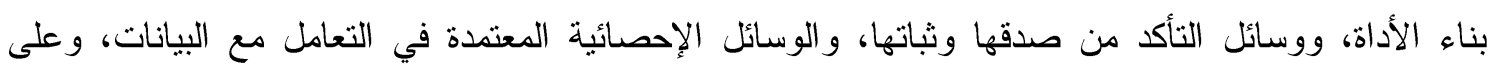
النحو الآتي:أولاً: منهج البحث: الاتي:

اختار الباحث المنهج الوصفي، لأنه يتلاعم وطبيعة بحثه، إذ أن وصف المشكلة القائمة مثلما هي عليه

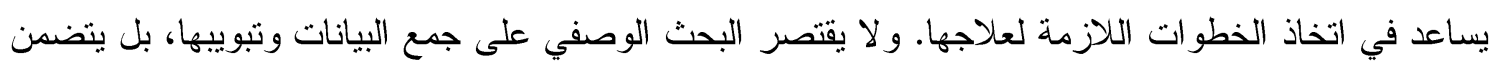

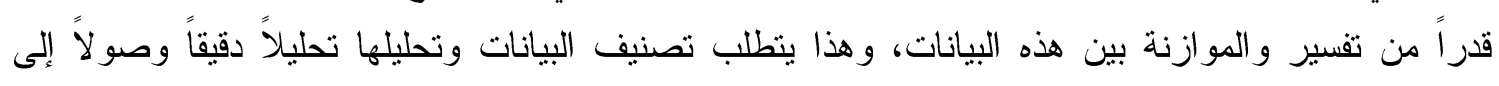
تعميمات

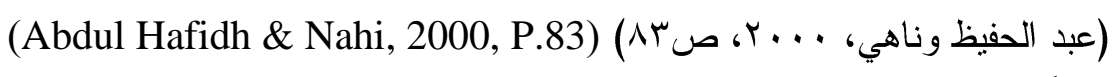
ثانياً: مجتمع البحث وعينته:

بهدف تحديد مجتمع البحث فقد قام الباحث بجمع المعلومات و البيانات من رئاسة جامعة ديالى و الكليات

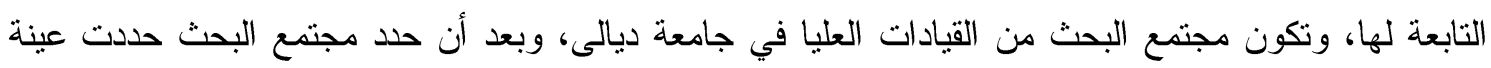

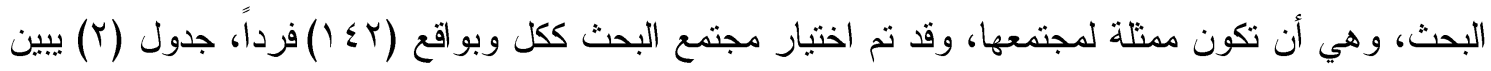
توزيع عينة البحث: 
جدول (ז)

توزيع عينة البحث وبحسب النسبة المئوية

\begin{tabular}{|c|c|c|c|}
\hline النسبة المئوية & العدد & المنصب الوظيفي & $ت$ \\
\hline$\% \cdot . \vee$. & 1 & رئيس جامعة & 1 \\
\hline$\% 1 . \varepsilon 1$ & r & مساعد رئيس جامعة & r \\
\hline$\% 9 . \wedge 7$ & $1 \leq$ & عميد & r \\
\hline \%r!.lr & $r$. & معاون عميد & $\varepsilon$ \\
\hline$\% \circ r .11$ & $V \varepsilon$ & رئيس قسم & 0 \\
\hline$\% 1 \leqslant . \vee q$ & rr & مدير قسم/مركز & 7 \\
\hline$\% 1 \ldots$ & $1 \leqslant r$ & جمــــــــــــوع & \\
\hline
\end{tabular}

ثالثاً: أداة البحث:

بما أن البحث الحالي يهدف إلى التعرف على إمكانية تطبيق معايير الجودة الثاملة في جامعة ديالى من

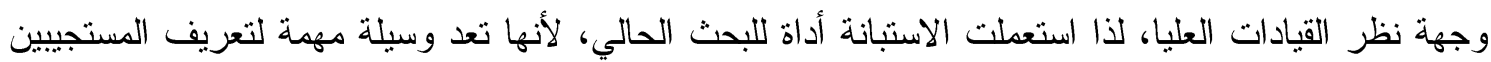
لمثنيرات مختارة ومرتبة بعناية بقصد جمع البيانات (فان دالين، (Daline,1985,P.395)، وأعدّ الباحث قائمة بالجو انب و الفقزات اللازمة لذلك ، على بلى وفق الإجر اءعات الآتية:

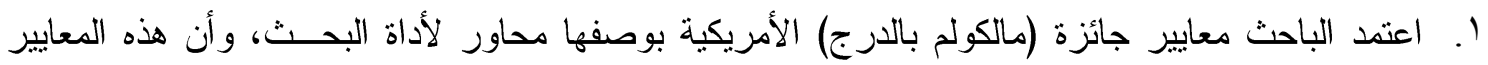

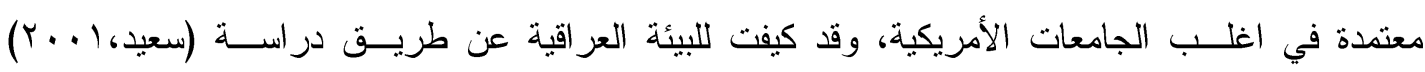
ودر اسة

(Saeed,2001)

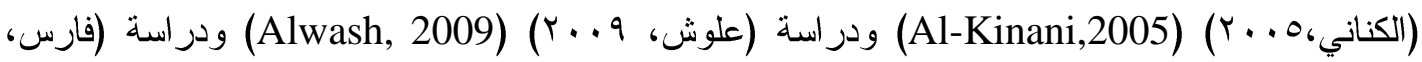
.(Faris, 2009) (r...9 r. الاطلاع على بعض الدراسات و البحوث المحلية والعربية والاجنبية السابقة ذات الصلة بموضوع البحث، وضم قسم منها في الجزء الخاص بالدر اسات السابقة (الفصل الثاني) في الدراسة الحالية.

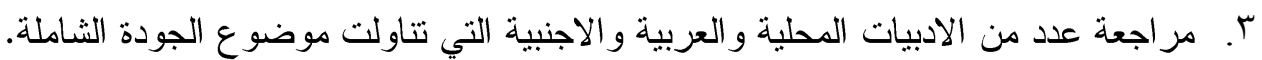

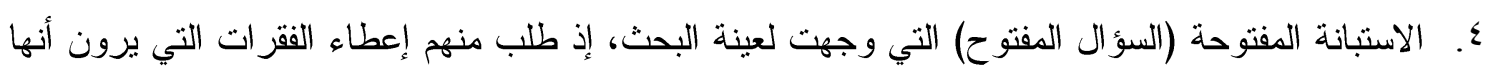
مناسبة لكل معيار من المعايير الرئيسة. ○. تو اصل الباحث مع عدد من الأساتذة و المتخصصين في مجال الجودة و الادارة و التعليم.

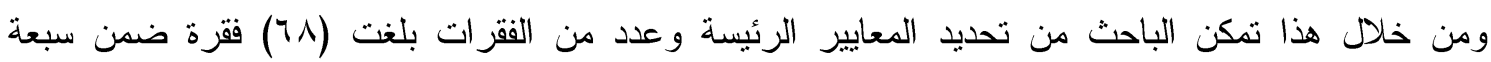
معايير. 


\section{رابعاً: صدق الأداة}

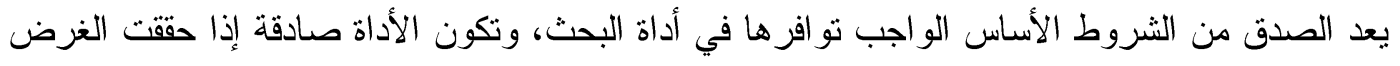

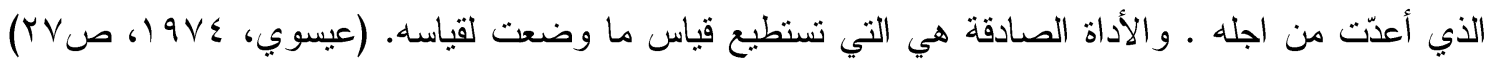

(Essawi,1974,P.27)

وقد عرض الباحث فقرات الاستبانة التي أعدت على عدد من المحكمين لمعرفة صلاحية كل فقرة من الفقرات أو عدم صداحيتها، وبعد ان حصل الباحث على ملاحظات الخبر اء وآر ائهر حذفت فقرة واحدة وعدلت

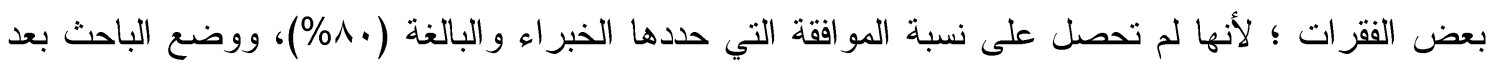

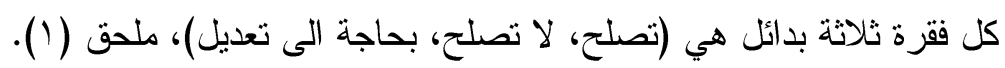

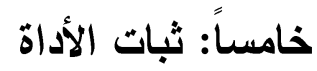

لغرض التحقق من ثبات أداة البحث الحالي، اعتمد الباحث أسلوب الاتساق يعني ثبات الفقرات الداخلي

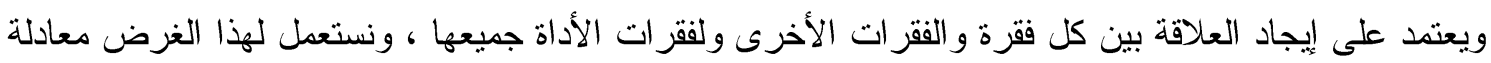

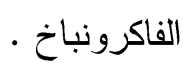
وبناء على ما نقدم فأن معامل الثبات بطريقة الفاكرونباخ التي بلغت (1). • •) تعد نسبة مقبولة، إذ إن النسبة

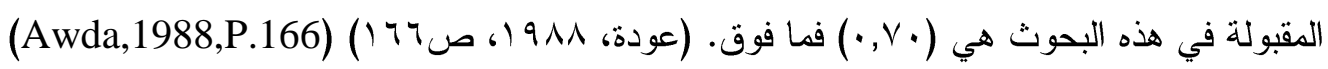

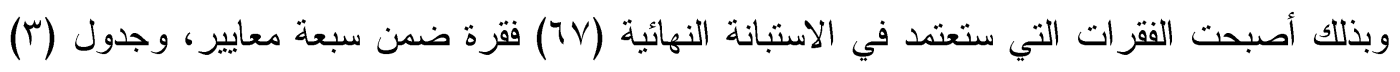
يبين النسب المئوية لكل محور وعدد الفقرات.

جدول (r)

عدد فِقرات الاستبانة ونسبتها المئوية موزعة بحسب المعايير

\begin{tabular}{|c|c|c|c|c|}
\hline نسبتها المئوية & ارقام الفِقر ات & عدد الفِقرات & المعايير & ت \\
\hline$\% \backslash 7 .\{1$ & $11-1$ & 11 & القيادة الإدارية & 1 \\
\hline$\%) \leq .94$ & $r-1 r$ & 1. & 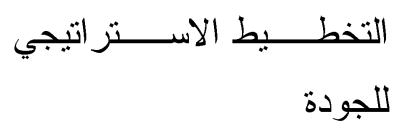 & $r$ \\
\hline$\% 11.9 \leq$ & $r q-r r$ & $\wedge$ & إدارة المعلومات الإدارية & $r$ \\
\hline$\%) \leq .94$ & rq-r. & 1. & إدارة الموارد البشرية & $\varepsilon$ \\
\hline$\%) r . \leqslant$ & $\varepsilon \wedge-\varepsilon$. & 9 & إدارة العمليات & 0 \\
\hline$\%) \leq .94$ & $0 \wedge-\leqslant 9$ & 1. & ضمان الجودة & 7 \\
\hline \%וז & $7 V-09$ & 9 & التركيز على المستفيد & V \\
\hline$\% 1 \ldots$ & & TV & المجموع & \\
\hline
\end{tabular}




\section{سادساً: تطبيق الأداة}

وزع الباحث الاستبانة على عينة البحث في رئاسة جامعة ديالى و الكليات التابعة لها، فقد وزع (rك ()

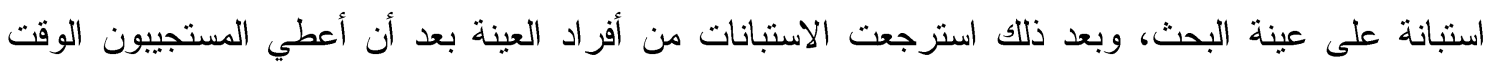

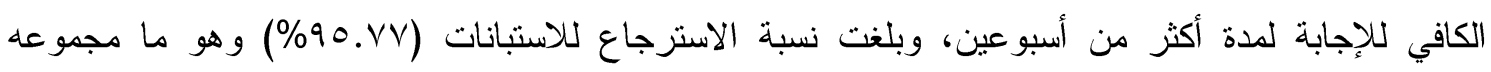

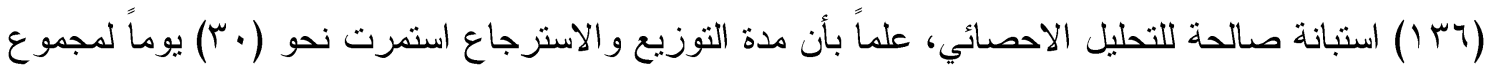
أفراد العينة، وقد اعتمد الباحث مقياساً خماسياً لإجابة فقرات الاستبانة الذي يطلب فيه من المستجيبين اختيار المستوى الذي يرونه مناسباً للإجابة، وهذا المدرج مكون من خمسة مستويات، وقد كممت هذه الاختبارات

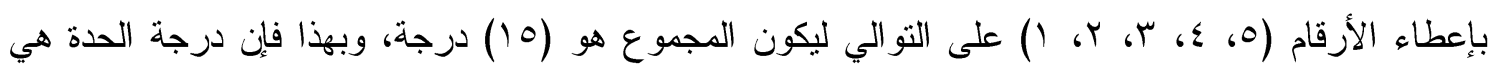

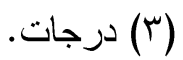

سابعاً: الوسائل الإحصائية 1 - مربع كاي (Chi-square) لاختبار صلاحية الفقرات من استجابات المحكمين عند مستوى دلالة (0., •)

$$
\begin{aligned}
& \text { ‘) (التكر ارات المشاهدة - التكر ارات المتوقعة) }
\end{aligned}
$$

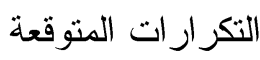

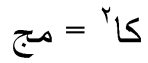

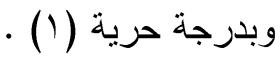

r- معادلة ألفا كرونباخ استخدمت لحساب الثبات بمعنى الاسنقر ار للمعايير و الأداة ككل.

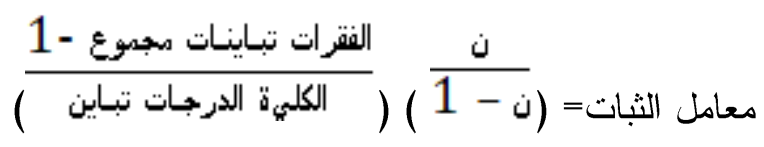

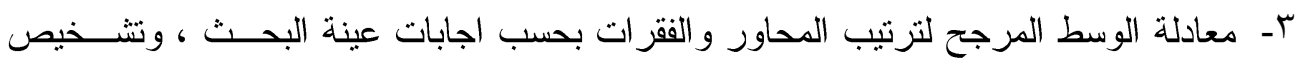

جوانب القوة والضعف بحسب المعيار المتبنى في الدر اسة الحالية.

I

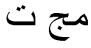

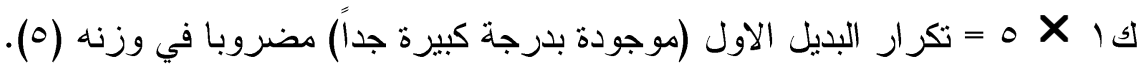

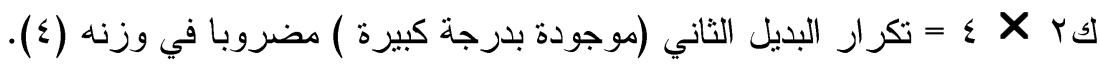

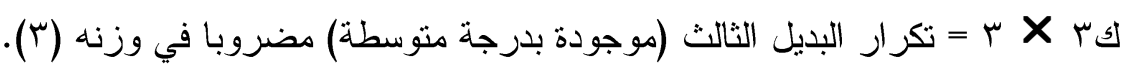

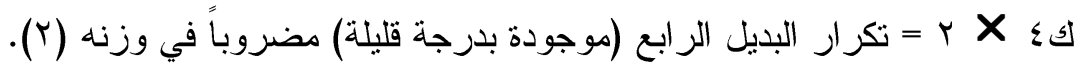

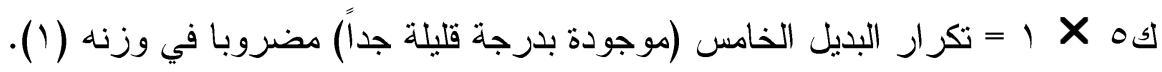

$$
\begin{aligned}
& \text { مج ت = مجموع التكرارات . }
\end{aligned}
$$

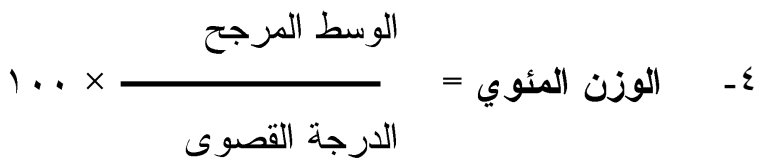

الدرجة القصوى هي أعلى درجة في المقياس ومقدارها ( ه ) . 


\section{الفصل الرابع}

عرض النتائج ومناقشتها:-

هدف البحث: النتائج المتعلقة بــ(تعرف درجة إمكانية تطبيق معايير الجودة الثاملة في جامعة ديالى من وجهة نظر القيادات العليا) يبين جدول (ع) ان قيمة الوسط المرجح والوزن المئوي العام بلغ (بو.؟ب) وسط ديط

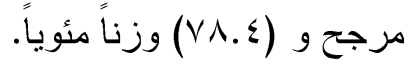

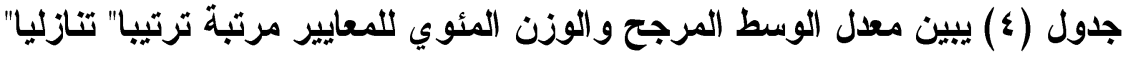

\begin{tabular}{|c|c|c|c|c|}
\hline الوزن المئوي & الوسط المرجح & المعاييز & التسلسل الحالي & التسلسل السابق \\
\hline NI. & $\varepsilon . \cdot V$ & التزكيز على المستقيد & 1 & $\mathrm{~V}$ \\
\hline NI.r & $\varepsilon .+7$ & القيادة الإدارية & r & 1 \\
\hline$\vee 9.7$ & $r .91$ & إدارة المو ارد البشرية & r & $\varepsilon$ \\
\hline 19 & $r .90$ & إدارة المعلومات الإدارية & $\varepsilon$ & r \\
\hline$\vee \wedge .7$ & $r .9 \pi$ & التخطيط الاستز اتيجي للجودة & 0 & r \\
\hline Vo & r.Vo & ضمان الجودة & 7 & 7 \\
\hline$V$ VT. & r.TV & إدارة العمليات & V & 0 \\
\hline$\vee \wedge . \varepsilon$ & r.9r & \multicolumn{3}{|c|}{ المعدل العام } \\
\hline
\end{tabular}

أما فيما يتعلق بإمكانية تطبيق معايير الجودة الثاملة لكل فقرة من الفقرات كانت كالاتي:-

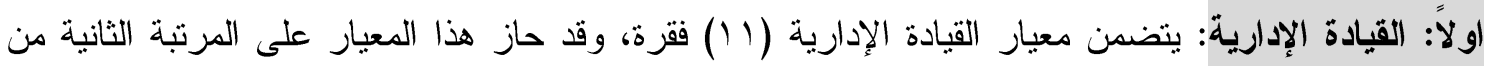

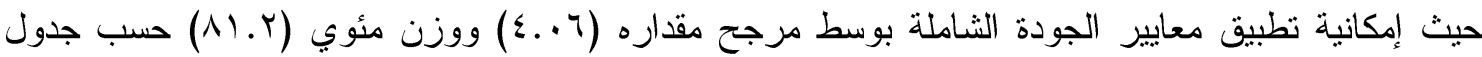

جدول (•)يبين الوسط المرجح والوزن المئوي لفقرات معيار القيادة الادارية مرتبة تنازلياً

\begin{tabular}{|c|c|c|c|}
\hline 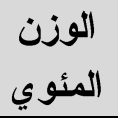 & المرجط & \multicolumn{2}{|l|}{ المعايير و الفقرات } \\
\hline \multicolumn{4}{|c|}{ ولاً: القيادة الإدارية } \\
\hline $9 \leqslant$ & $\varepsilon . V$ & اقتتاع إدارة الجامعة بدعم تطبيق معايير الجودة الثاملة & .1 \\
\hline 9. & Ł.० & نشر ثقافة الجودة الشاملة بين جميع العاملين. &.$r$ \\
\hline$\Lambda \uparrow$ & $\varepsilon . \mu$ & الالتز ام بأخلاقيات العمل لاسيما العدالة و المساو اة. & $r^{r}$ \\
\hline$\wedge r$ & $\varepsilon .1$ & توفر إدارة الجامعة الأنظمة الحديثة لتطبيق معايير الجودة الثاملة. &.$\varepsilon$ \\
\hline$\Lambda \cdot r$ & $\varepsilon .+10$ & تشجع إدارة الجامعة العمل بروح الفريق الواحد بين جميع الأقسام. & .0 \\
\hline Vq. r & r.97 & تععل إدارة الجامعة للتعرف على النماذج و التجارب الناجحة في مجال تطبيق معايير & .7 \\
\hline $\mathrm{v \wedge}$ & $r .9$ & تتو اصل مع الطلبة لتحقيق منطلباتهم وحاجاتهم. &.$\vee$ \\
\hline VV & r.10 & الاخذ بآر اء رؤساء الأقسام عند اتخاذ قرار اتها. &.$\wedge$ \\
\hline $\mathrm{VY}$ & r.А & توفر المناخ التنظيمي والبيئة التعليمية المناسبة لضبط العملية التزبوية و التعليمية. & .9 \\
\hline$\vee 0.1$ & r.vq & توفر قيادات إدارية كفوءة على مستوى رؤساء الأقسام العلمية والادارية. & $.1 \cdot$ \\
\hline Vo. & r.VV & تفوض إدارة الجامعة جزء من صدلاحياتها للعاملين لدى تطبيق معايير الجودة الثاملة. & .11 \\
\hline Al.r & $\varepsilon .7$ & المعدل العام & \\
\hline
\end{tabular}


يتضح من جدول (0) ما يأتي :

إن الفقرة تسلسل (1) التي تتص على (اقتناع إدارة الجامعة بدعم نطبيق معايير الجودة الثاملة) حازت

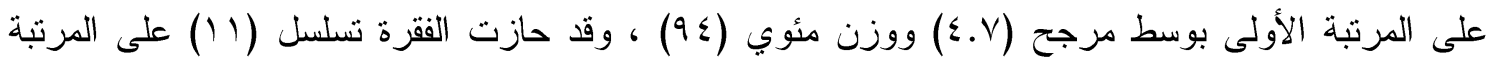

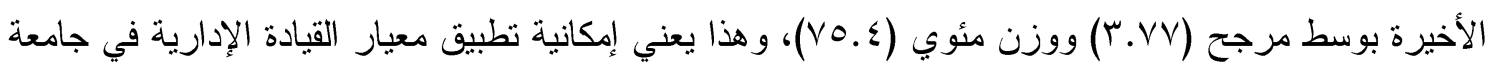

ديالى

ثاتياً : التخطيط الاستر اتيجي للجودة: يتضمن معيار التخطيط الاستراتيجي للجودة (• () فقرات، وقد حاز هذا

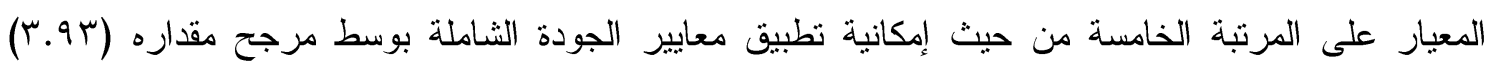

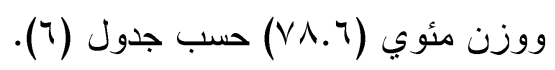

جدول (†) يبين الوسط المرجح و الوزن المئوي لفقرات التخطيط الاستر اتيجي للجودة مرتبة تنازلياً

\begin{tabular}{|c|c|c|c|}
\hline 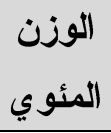 & المرجط & \multicolumn{2}{|l|}{ المعاييز و الفقر ات } \\
\hline \multicolumn{4}{|c|}{ ثانياً : التخطيط الاستر اتيجي للجودة } \\
\hline 9. & $\varepsilon .0$ & رسم الخطة الاستر اتيجية وفق الإمكانات المادية والبشرية للجامعة. & .1 \\
\hline$\wedge \wedge . \wedge$ & $\varepsilon . \varepsilon \varepsilon$ & تضع إدارة الجامعة أهدافها أمام جميع العاملين على نحو و اضح ومبسط. & r \\
\hline$\wedge \wedge$ & $\varepsilon . \varepsilon$ & تحرص إداد الخطط الاستر التيجية الجامعة على اشر الك عمداء الكليات ومدر اء التشكيلات الإدارية المختلفة في & $r$ \\
\hline$\wedge 7$ & $\varepsilon . r$ & تُتابع تتفيذ الخطط وضبطها على وفق منطلبات الجودة الشاملة. &.$\varepsilon$ \\
\hline$\wedge$. & $\varepsilon$ & تو افر بيئة تتظيمية للجامعة ملائمة لتطبيق مفاهيم الجودة الثشاملة & .0 \\
\hline$\checkmark V$ & r.^o & تطور الخطط و البرامج المنفذة من أجل تحسين جودة مخرجاتها على المستوى البعيد. & .7 \\
\hline Vo. & r.VV & تعتمد خطة خمسية يجري تحقيقها ضمن التوقيتات الزمنية المحددة. &. $\mathrm{v}$ \\
\hline$V \leqslant$ & r.V & مشاركة جميع العاملين بشكل دوري لتنفيذ الخطة الاستر اتيجية للجامعة. &.$\wedge$ \\
\hline $7 \varepsilon$ & r.r & تضع خطة استر اتيجية تتضمن سرعة الاستجابة لمو اجهة التغير ات المحتملة. & .9 \\
\hline Tr & r.l & تعتمد إدارة الجامعة مبدأ اللامركزية الإدارية وتفويض الصداحيات. & 1 . \\
\hline$\vee \wedge .7$ & $r .9 r$ & المعدل العام & \\
\hline
\end{tabular}

يتضح من جذول (†) ما يأتي :

أن الفقرة تسلسل (1) التي تتص على (رسم الخطة الاستراتيجية وفق الإمكانات المادية والبشرية

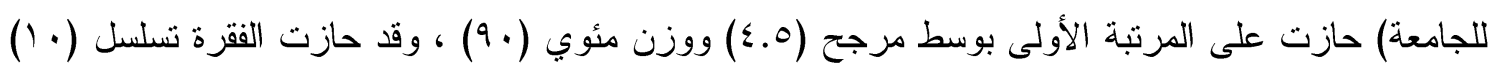

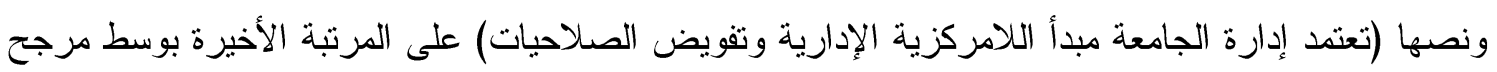

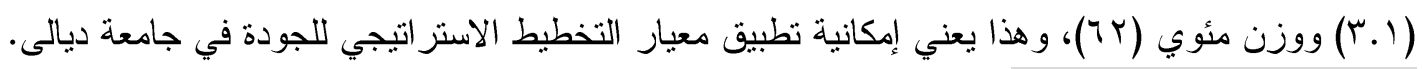

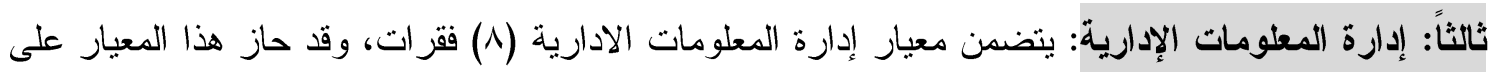

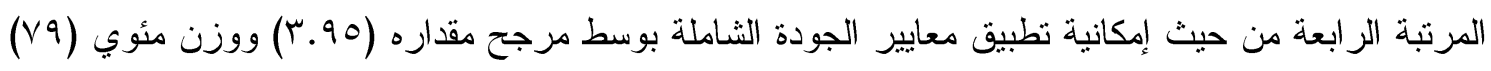

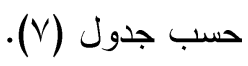


جذول (V) يبين الوسط المرجح والوزن المئوي لفقرات إدارة المعلومات الإدارية مرتبة تنازلياً

\begin{tabular}{|c|c|c|c|}
\hline المئوي & المرجح & \multicolumn{2}{|l|}{ المعايير والفقرات } \\
\hline \multicolumn{4}{|c|}{ ثالثاً : إدارة المعلومات الإدارية } \\
\hline$\Lambda \Lambda$ & $\varepsilon . \varepsilon$ & توفر وسائل الاتصال الالكترونية الحديثة مثل من اجل توفير المعلومات. & .1 \\
\hline$\Lambda V$ & S.ro & توفر إدارة الجامعة الكادر المتخصص في نظم المعلومات و البيانات &.$r$ \\
\hline$\wedge 7$ & 纟.r & توفر إدارة الجامعة قاعدة معلوماتية متقنة خاصة بالمستفيدين من الجامعة. & r \\
\hline$\wedge \varepsilon$ & $\varepsilon . Y$ & تعتمد نظاماً معلوماتياً الكترونياً متكاملاً يعتُمد عليه في اتخاذ القرار ات بدقة. & $\varepsilon$ \\
\hline VV & r.10 & تعمل الجامعة على تصنيف البيانات على وفق نماذج إحصائية فعالة. & .0 \\
\hline VY & r.А & توثق إجر اءات العملية التعليمية للرجوع إليها عند الحاجة. & .7 \\
\hline v. & r.o & توفر المعلومات بالوقت المناسب لمن يطلبها. &.$\vee$ \\
\hline $7 \varepsilon$ & $r . r$ & امتلالك الجامعة للبيانات الخاصة بتكاليف الجودة الثاملة. &.$\wedge$ \\
\hline Vq & r.90 & المعدل العام & \\
\hline
\end{tabular}

يتضح من جدول (V) ما يأتي :

إن الفقرة تسلسل (1) التي تتص على (توفر وسائل الاتصال الالكترونية الحديثة مثل من اجل توفير

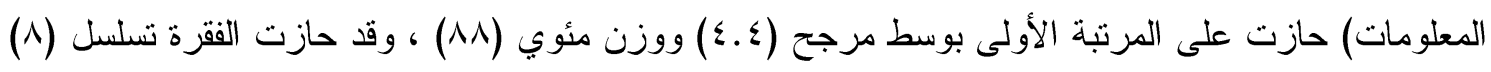

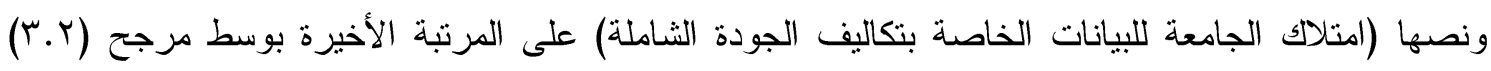
ووزن مئوي (§ 7)، وهذا يعني إمكانية تطبيق معيار إدارة المعلومات الادارية في جامعة ديالى.

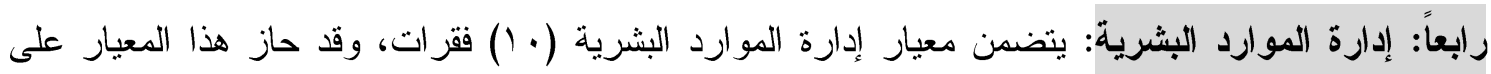

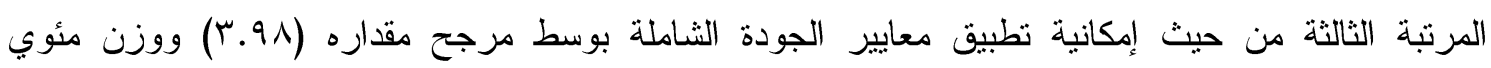

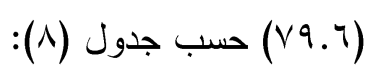

جدول (^) يبين الوسط المرجح والوزن المئوي لفقرات إدارة الموارد البشرية مرتبة تنازلياً

\begin{tabular}{|c|c|c|c|}
\hline المئوي & المرجط & \multicolumn{2}{|l|}{ المعايير والفقرات } \\
\hline \multicolumn{4}{|c|}{ رابعاً : إدارة الموارد البثرية } \\
\hline 91 & $\varepsilon .7$ & تدرب العاملين باستمر ار من أجل التكيف مع النطور ات الحديثة في الجانب الإداري. & .1 \\
\hline 9. & «.० & تطور مهار ات منتسبيها ومعارفهج من اجل تحسين جودة العمل. & . \\
\hline 11 & 纟. & تثجيع إدارة الجامعة العاملين عل المبادرة بالمشاريع و الأفكار الناجحة لتوكبد الجودة فيها. & $r^{r}$ \\
\hline 17 & $\varepsilon . r$ & تعتمد قو اعد مكتوبة تحدد الأخلاقيات المهنية لجميع العاملين فيها. & $\varepsilon$ \\
\hline 10 & S.Yo & يستعمل أعضاء هيأة التنريس التقنيات الحديثة في التدريس. & .0 \\
\hline$\wedge$. & $\varepsilon$ & تحدد إدارة الجامعة حاجتها إلى الموارد البشرية بموجب معايير قياسية للجودة الثاملة & .7 \\
\hline Vo.乏 & r.V. & تعتمد نظاماً " للحو افز و المكافآت المادية و المعنوية تقدير أ للجهود المنمبزة للعاملين. &. $\mathrm{V}$ \\
\hline $\mathrm{ve}$ & r.o & تعتمد نظاماً لتهيئة العاملين الجدد و أعدادهم أعداداً يمكنهم من فهم طبيعة العمل. &.$\wedge$ \\
\hline 74 & r.r & تحديد الاحتياجات التدريبية للعاملين وفق مصفوفة الكفاءة الخاصة بقياس أداء العاملين. & .9 \\
\hline T乏 & r.r & يستعمل الموظفون الثقنيات الحديثة بصورة فعالة في عملهم. & .1 \\
\hline V9.7 & $r .91$ & المعدل العام & \\
\hline
\end{tabular}


يتضح من جدول (^) ما يأتي: أن الفقرة تسلسل (1) التي تتص على (تدرب العاملين باستمرار من اجل التكيف مع التطورات الحديثة في الجانب الإداري) حازت على المرنبة الأولى بوسط مرجح (7. ؛) ووزن مئوي (19)، وقد حازت الفقرة تسلسل (• (1) ونصها (يستعمل الموظفون التقنيات الحديثة بصورة فعالة في عمله) على المرتبة الأخيرة بوسط مرجح

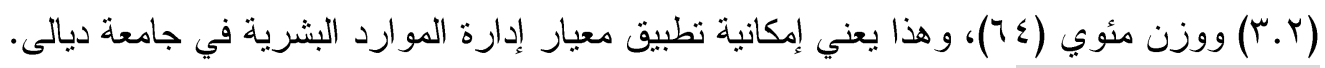

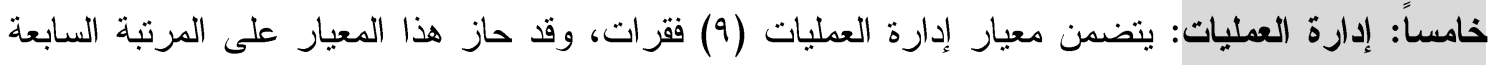

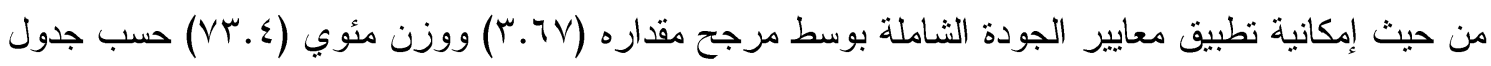

جدول (a) (a) (a)

يبين الوسط المرجح والوزن المئوي لفقرات إدارة العمليات مرتبة تنازلياً

\begin{tabular}{|c|c|c|c|}
\hline 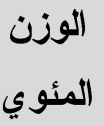 & المرجط & \multicolumn{2}{|l|}{ المعايير و الفقر ات } \\
\hline \multicolumn{4}{|c|}{ خامساً : إدارة العمليات } \\
\hline 10 & S.Yo & تسعى إدارة الجامعة لخفض التكلفة لإدارة مختلف العمليات في الجامعة. & .1 \\
\hline Ar.r & «.11 & تصميم جميع العمليات على نحوِ يؤدي إلى تلبية حاجات المستقيدين ورغباتهم وتحقيق رضاهم &.$r$ \\
\hline A. & $\varepsilon$ & توفر التكنولوجيا الحديثة من اجل الارتقاء بالعملية التعليمية. &.$^{r}$ \\
\hline vo & r.vo & التركيز على جودة العمليات الإدارية بدلاً من التركيز على نتائجها &.$\varepsilon$ \\
\hline$V \varepsilon$ & r.v & تمنلك الجامعة بر امج تعليمية متطورة و اضحة يمكن تطبيقها. & .0 \\
\hline$\checkmark \cdot$ & r.o & تعتمد دليل و اضح لمستوى التأهيل العلمي و المهني في البرامج التعليمية. & .7 \\
\hline 71 & r. & تصمم البرامج التعليمية على وفق معايير الجودة الثاملة. &. $\mathrm{V}$ \\
\hline$T \varepsilon$ & r.r & و المخماد طر ائق القياس الكمي و التحليل الإحصائي لتقويم مستوى الجودة المنجز للعمليات &.$\wedge$ \\
\hline $7 r$ & r.l & تحدد مستويات الأداء و الاسترشاد بها في تصحيح ما قد ينحرف عن الأداء المتوقع. & .9 \\
\hline Vr.\& & $\mathrm{r.7V}$ & 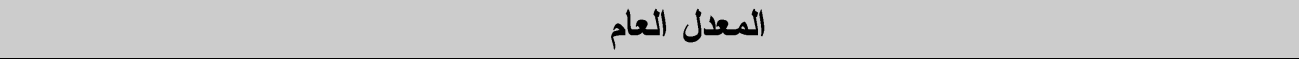 & \\
\hline
\end{tabular}

يتضع من جدول (9) ما يأتي :

أن الفقرة تسلسل (1) التي تتص على (تسعى إدارة الجامعة لخفض التكلفة لإدارة مختلف العمليات في

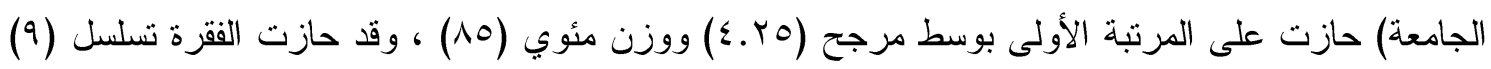

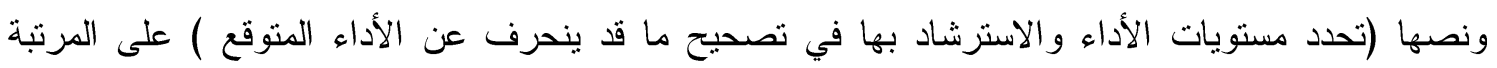

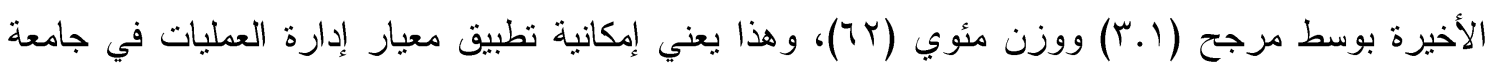


سادساً: ضمان الجودة: بتضمن معيار ضمان الجودة (• () فقرات، وقد حاز هذا المعيار على المرتبة السادسة

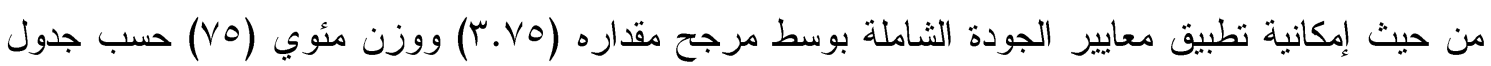

جدول ( • 1) يبين الوسط المرجح والوزن المئوي لفقرات ضمان الجودة مرتبة تنازلياً

\begin{tabular}{|c|c|c|c|}
\hline المئوي & المرجط & \multicolumn{2}{|l|}{ المعايير و الفقرات } \\
\hline \multicolumn{4}{|c|}{ سادساً : ضمان الجودة } \\
\hline 19 & «.々० & تأسيس مجلس إدارة عليا لمتابعة عمليات التحسين في الجامعة & .1 \\
\hline 17 & \&.r & تكوين فرق عمل من إداريين و أكاديميين لوضع خطط التحسين المستمر للجودة &.$r$ \\
\hline$\Delta r$ & $\$ .10$ & تعتمد نوصيفاً وظيفياً (يحدد المسؤوليات و الو اجبات و الأدو ار). & r \\
\hline 11.1 & $\varepsilon . .9$ & تجري المفاضلة بين المتقدمين للتوظيف على أسس موضوعية تستند إلى الكفاءة في الاختصاص. &.$\varepsilon$ \\
\hline$\wedge$. & $\varepsilon$ & نوفر مختبرات علمية حديثة تتو افق مع معايير الجودة الثاملة. & .0 \\
\hline $\mathrm{V} \varepsilon$ & r.V & الالتز ام بمعايير الجودة الشاملة عند تقويم (المدخلات-العمليات- المخرجات). & .7 \\
\hline 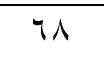 & r.乏 & تنتاسب المو ارد المالية مع متطلبات تطبيق ضمان الجودة داخل المؤسسة الجامعية. &. $\mathrm{V}$ \\
\hline 74 & r.r & تركز على نوعية مدخلاتها للارتقاء بعملياتها ومخرجاتها. &.$\wedge$ \\
\hline$T r$ & $r .1$ & بالإمكان مقارنة مخرجات الجامعة مع محكات عالمية. & .9 \\
\hline 7. & r & تمنالك الجامعة مصفوفة مخاطر فاعلة للقيام بإجر اءات وقائية و علاجية للأخطاء منوقعة الحدوث & .1 . \\
\hline Vo & r.vo & المعدل العام & \\
\hline
\end{tabular}

يتضح من جدول (· (1) ما يأتي:

إن الفقرة تسلسل (1) التي تتص على (تأسيس مجلس إدارة عليا لمتابعة عمليات التحسين في الجامعة)

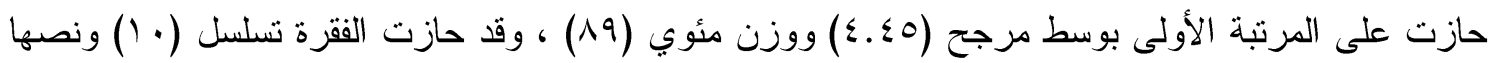

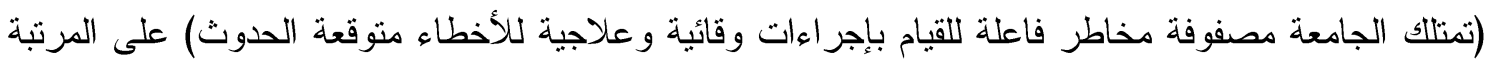
الأخيرة بوسط مرجح (r) ووزن مئوي (· (7)، و هذا يعني إمكانية تطبيق معيار ضمان الجودة في جامعة ديالى.

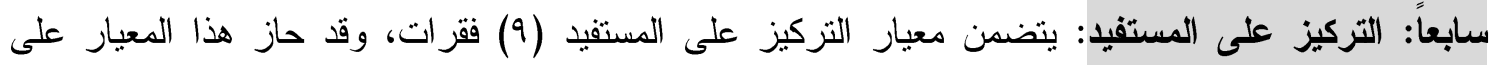

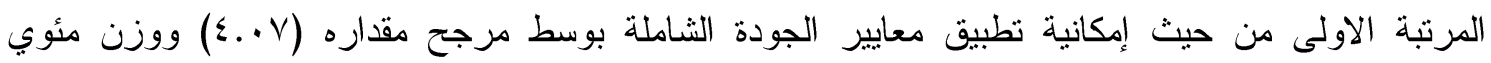

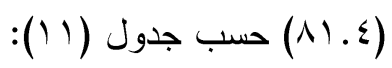

جدول (11) يبين الوسط المرجح والوزن المئوي لفقرات التركيز على المستفيل مرتبة تنازلياً

\begin{tabular}{|c|c|c|c|}
\hline 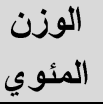 & المرجح & \multicolumn{2}{|l|}{ المعايير والفقرات } \\
\hline \multicolumn{4}{|c|}{ سابعاً : التركيز على المستفيد } \\
\hline 9 . & $\varepsilon .0$ & توفر الجامعة الخدمات لطلبتها (صحية، إبكان، قاعات در اسية،...الخ). & .1 \\
\hline$\wedge \wedge . \wedge$ & $\varepsilon . \varepsilon \varepsilon$ & التركيز على الطالب كمحور للعملية التعليمية التعلمية في الجامعة. &.$r$ \\
\hline 14.7 & $\varepsilon . \mu r$ & تحرص القيادة الجامعية على الاهتمام بمخرجاتها كماً ونو عاً لتحقيق رضا المستفيدين. &.$^{r}$ \\
\hline 17 & $\varepsilon .{ }^{\mu}$ & التذريس. بيئة تعليمية تتاسب مع متطلبات ضمان الجودة من اجل تحقيق رضا الطلبة وأعضاء هيئة &.$\varepsilon$ \\
\hline$\wedge \varepsilon$ & $\varepsilon .4$ & إجر اء الدر اسات و البحوث للتعرف على حاجات المستفيدين ورغباتهز. & .0 \\
\hline A. & $\varepsilon$ & الاخذ بآر اء المستفبدين لتطوير وتغيير الخدمات الجامعية. & .7 \\
\hline
\end{tabular}




\begin{tabular}{|c|c|c|c|}
\hline V7 & $r . \wedge$ & تحرص القيادة الجامعية على در اسة شكاوى المستفيدين من دون إهمالها أو تأخير ها. &. $\mathrm{V}$ \\
\hline Vr & r.t & تعزيز العلاقات مع المستفيدين ضمن البيئة الداخلية و الخارجية للمؤسسة الجامعية. &.$\wedge$ \\
\hline $\mathrm{V} \cdot$ & $r .0$ & توفر الموارد المادية و البشرية لتتو افق مع تلبية حاجات المستفيدين. & .9 \\
\hline A). & $\varepsilon \ldots v$ & المعدل العام & \\
\hline
\end{tabular}

يتضح من جدول (11) - 11) ما يأتي:

إن الفقرة تسلسل (1) التي تنص على (توفر الجامعة الخدمات لطلبتها (صحية، إسكان، قاعات

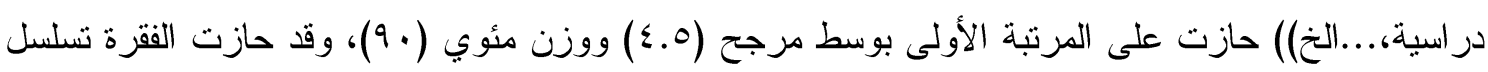

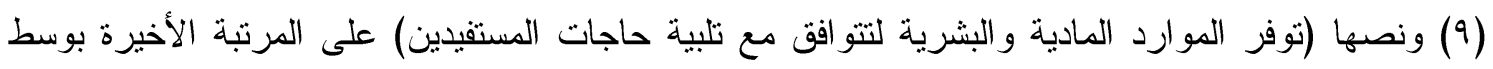

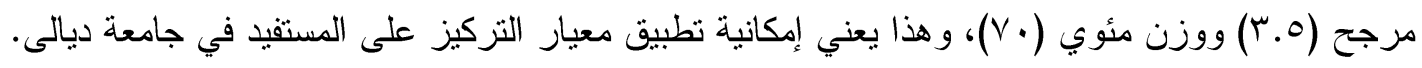
الاستتناجات: في ضوء نتائج البحث استتنج الباحث ما يأتي: ا - يتزتب على النتائج التي توصل اليها الباحث انه بالإمكان تطبيق معايير الجودة الثناملة في جامعة ديالى إذا

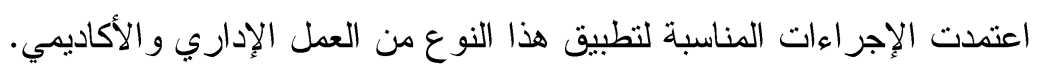

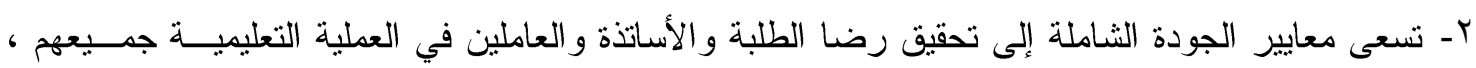

$$
\text { وتهدف إلى رضا جهات العمل التي توظف الخريجين. }
$$

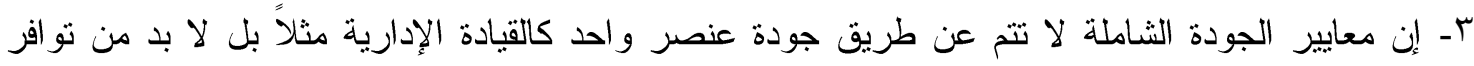

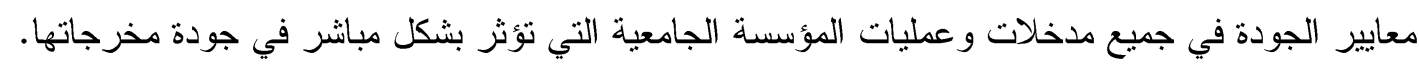

عـ أصبح تطبيق إدارة الجودة الثاملة ضرورة ملحة بهدف تطوير إدارة المؤسسات الجامعية. هـ تمتلك جامعة ديالى الخطط المناسبة لاعتماد آراء أعضاء هيأة التدريس، و الطلبة، و الخريجين، و المستفيدين

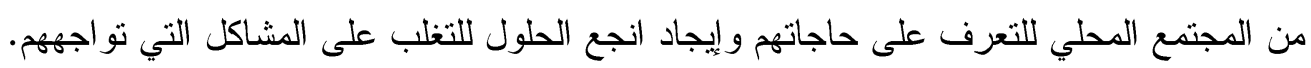

\section{التوصيات:}

في ضوء نتائج البحث يوصي الباحث بما يأتي:-

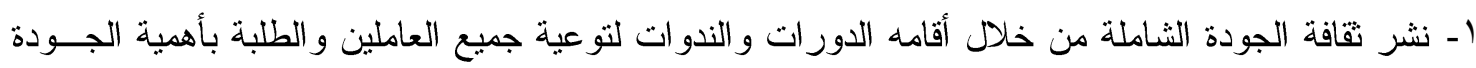
الثاملة للمؤسسة التعليمية. r- تهيئة الموارد البشرية اللازمة لتطبيق معايير الجودة الثاملة من خلال تدريب وتطوير المهارات الخاصـــة بالعاملين r- توفير الإمكانات المالية التي تنهم في تطبيق معايير الجودة الثاملة في جامعة ديالى.

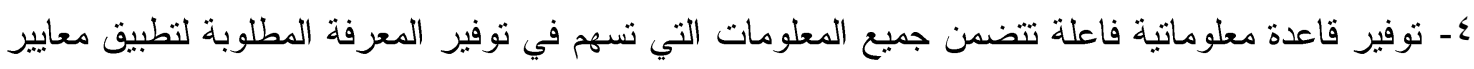
الجودة الثاملة باقل جهذ ووقت مدكنين . ○ـ إنشاء نظام لتوفير المعلومات مفتوح ومبرمج، وتوفير شبكة معلومات داخلية وخارجية متطورة لكي تساعد في اتخاذ القرارات اللازمة في الكليتين. المقترحاث: - ات في ضوء نتائج البحث يقترح الباحث ما يأتي:- 
1 - إجر اء دراسات مشابهة لهذه الدر اسة في كليات وجامعات أخرى. r- إجر اء دراسات للوقوف على معوقات تطبيق معايير الجودة الثاملة في جامعة ديالى.

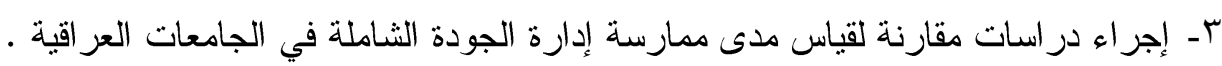

المصادر : • أبو عزيز، شادي عبد الله، (9 . . ب)، معايير الجودة في تصميم وإنتاج الوسائل والتكنولوجيا في التعليم

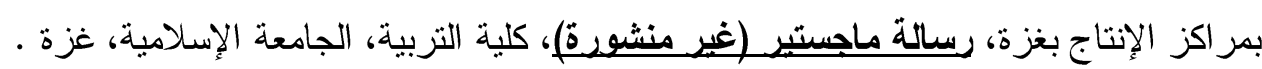

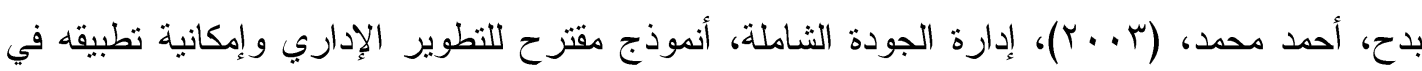
الجامعات الأردنية العامة، أطروحة دكتور اه (غير منشورة)، جامعة عمان العرة العربية للار اسات العليا، الأردن.

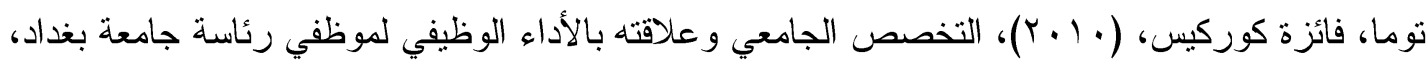

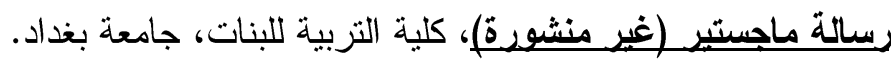

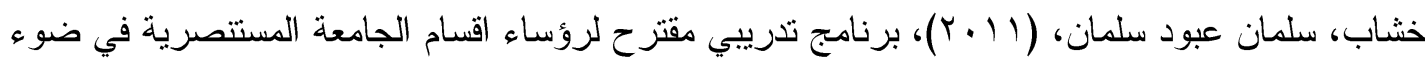
معايير الجودة الثاملة ، رسالة ماجستير (غير منشورة)، كلية التربية الاساسية، الجامعة المستتصرية.

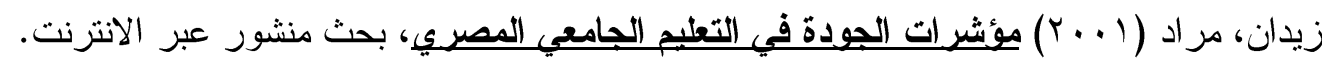

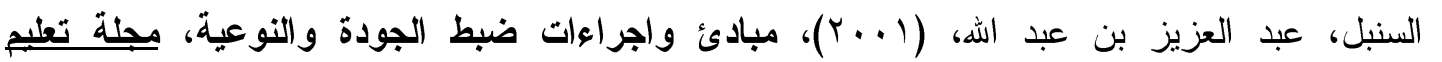

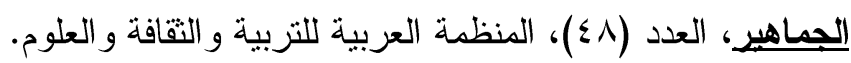

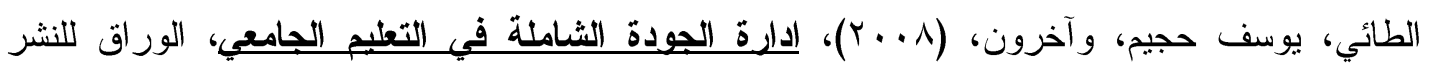
و التوزيع، عمان. عبد الحفيظ، إخلاص محمد وناهي، مصطفى حسين ( .... r)، طرق البحث العلمي و التحليل الإحصائي في

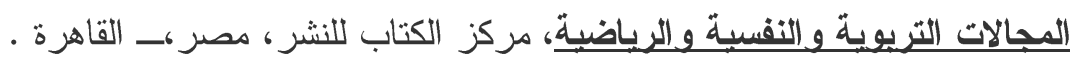

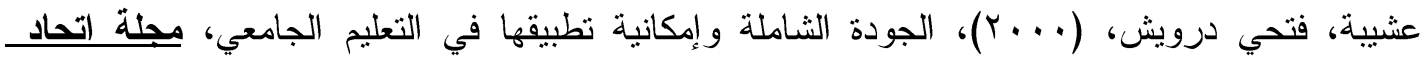

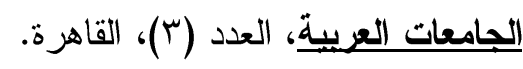

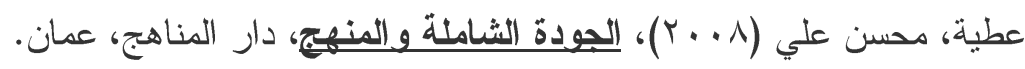

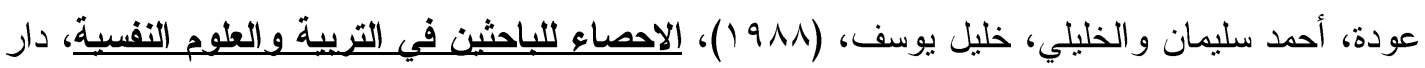
الفكر للنشر و التوزيع، عمان. عبسوي، عبدالرحمن محمد، (؟ (9V)، القباس والتجريب في التربية وعلم النفس، القاهرة ، دار النهضة العربية.

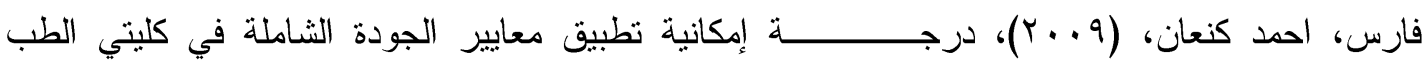
جامعتي بغداد و المستتصرية دراسة مقارنة ، رسالة ماجستير (غير منشورة)، كلية التزبية الاساسية، الجامعة المستنصرية. فان دالين، ديويولد، (910 ()، مناهج البحث في التربية وعلم النفس، ترجمة نبيل نوفل واخرون، ط سا،

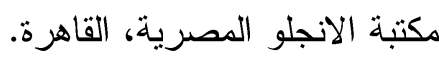

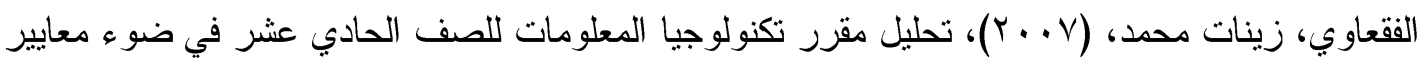

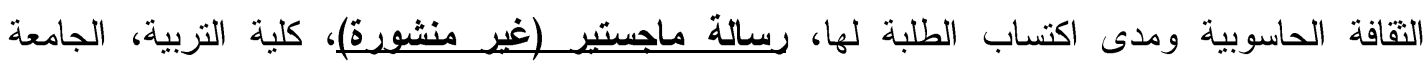
الإسـامية بغزة. 


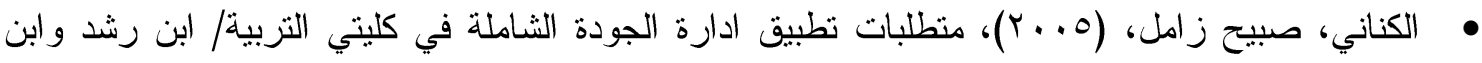

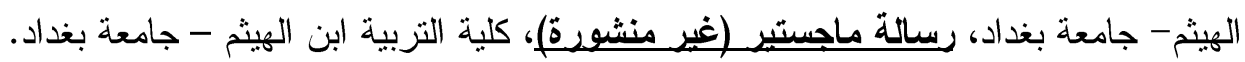

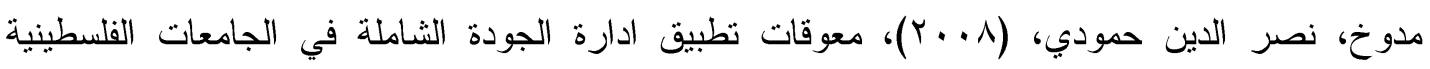

$$
\begin{aligned}
& \text { بمحافظات غزة وسبل التغلب عليها، رسالة ماجستير (غير منشورة )، كلية التربية، الجامعة الاسلامية. }
\end{aligned}
$$

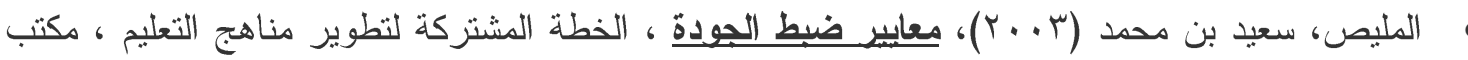

$$
\begin{aligned}
& \text { التزبية العربي لدول الخليج العربي ، الرياض. }
\end{aligned}
$$

- Brocka, B,. \& Brocka, S,. (1992). Quality Management : Implementing the Best Idea of the master, First

- David, L Goetsch (1994). Introduction to total Quality; Qualiry, Productivity, Competitireness, U.S.A : Prentice- Hall International Inc.

- Lewis, G and Smith, H (1997), Why Quality Improvement in Higher Education ,International Journal of Education, Vol.1, December

\section{References:}

- Abuaziz, Shady Abdullah (2009), Standards of quality in designing and producing means and technology in the educational centers in Gaza. Unpublished Master's degree thesis. College of Education. The Islamic University GAZA.

- Badah, Ahmed Mohammed (2003), Comprehensive Quality Management, A suggested Model of Administrative Development and the Possibility of applying it in the Jordanian Universities Unpublished Doctorate Dissertation, University of Amman of Higher studies Jordan.

- Toma. Faiza Korkis (2010), University Specialization and its relationship Functional Performance of employees of University of Baghdad. Unpublished Master's degree thesis, College of Education for Girls- University of Baghdad.

- Khashab, Salman Abood Salman (2011), A suggested Training Programme for Heads of Departments- Al- Mustansiriyah University in the light of Standards of comprehensive Quality - Unpublished, Master's degree thesis, College of Basic Education - AlMusrtansiriyah University.

- Zaidan, Murad (2001), Indices of Quality in the Egyptian University Education, Published paper via Internet.

- Al-Sunbal, Abdul Aziz Ibn Abdullah (2001), Principle and procedures of Quality control, Journal of the Education of the people, Issue (48), Arab Organization of Education, culture and science.

- Al- Taee, Yousef Hajeem, et.al. (2008), Management of Comprehensive Quality in the University Education, Al- Waraq of Publications and Distribution, Amman.

- Abdul Hafidh, Ikhlas Mohammed \& Nahi, Mostapha Hussein (2000), Methods of Scientific Research and the statistical Analysis in the Educational Psychological and Mathematical Fields, Al- Kitab center for publication, Egypt, Cairo.

- Usheiba, Fathi Darwish (2000), The comprehensive Quality and the Possibility of applying it in the University Education, Journal of Arab Universities Union, Issue (3), Cairo.

- Attiyah, Mohsen Ali (2008), The Comprehensive Quality and Methodology,Dar- AlManahij- Amman.

- Udah, Ahmed Sulaiman and Al- Khalili, Khalil Yousef (1988), Statistics used by researchers in the Educational and Psychological Sciences, Dar Al- Fakr for Publication and Distribution Amman.

- Essawi, Abdul Rahman Mohammed (1974), Measurement and Experimentation in Education and Psychology, Cairo Dar Al- NAHDHA Al- Arabia.

- Faris, Ahmed Kinaan (2009), The Degree of the Possibility of Applying Standards of Comprehensive Quality in College of Medicine - University of Baghdad and Al- 
Mustansiriyah University. Comparative study- Unpublished, Master's degree thesis, College of Basic Education, Al- Mustansiriyah University.

- Van Dalen, Deobold (1985), Methods of Research in Education and Psychology, Translated Nabil Nawfel, et. al., Edition (3), Anglo, Egyptian, Library, Cairo.

- Al- Faqawy, Zenaat Mohammed (2007), Analysis of textbook of Information Technology of the Eleventh grade in the light of standards of computing culture and the extent of students, learning, Unpublished Master's thesis, College of Education the Islamic University, GAZA.

- Al- Kinani, Sabih Zamel (2005), Requirements of Applying the Comprehensive Quality Management in College of Education/ Ibn Rushud and Ibn Al- Haitham - University of Baghdad. Unpublished Master's degree thesis, College Ibn Al- Haitham - University of Baghdad.

- Madookh, Nasr Al- Din Hamoodi (2008), Constraints of Applying The Comprehensive Quality Management in the Palestinian Universities in Gaza and ways of Overcoming them Unpublished Master's thesis, College of Education. The Islamic University.

- Al- Molees, Saees Ibn Mohammed (2003), Standards of Quality Control. The Joint plan of developing Methods of Education Bureau of the Arab Education of Arabian Gulf States, Riyadh.

\section{ملحق (1)}

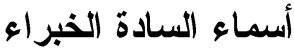

\begin{tabular}{|c|c|c|c|}
\hline مكان العمل & الاختصاص & 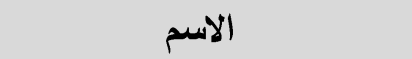 & $ت$ \\
\hline جامعة حلوان - كلية التربية & التربية المقارنة و الإدارة التعليمية & أ.د. إبر اهيم علي الزهيري & .1 \\
\hline جامعة ديالى - كلية العلوم الانسانية & قياس وتقويم & أ.د. عدنان محمود المهداوي & 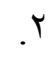 \\
\hline جامعة ديالى - كلية التزبية الاساسية & إدارة و اشر اف تزبوي & أ.د. علي إير اهيم الآوسي & r \\
\hline جامعة ديالى - كلية التربية الاساسية & طر ائق تدريس & أ.د. سلمى مجيد حميد &.$\varepsilon$ \\
\hline جامعة ديالى / كلية التربية الاساسية & فلسفة تربية & أ.م.د. اشر اق عيسى عبد & .0 \\
\hline جامعة ديالى - كلية التزبية الاساسية & علم النفس التزبوي & أ.م.د. اخلاص علي حسين & .7 \\
\hline جامعة ديالى / كلية التربية للعلوم الإنسانية & علم النفس التزبوي & أ.م.د. مظهر عبد الكريم سليم &.$\vee$ \\
\hline جامعة ديالى / كلية التربية للعلوم الإنسانية & طر ائق تدريس & أ.م. حسن حميد حسن &.$\wedge$ \\
\hline
\end{tabular}

